\title{
Sinopse de Pilotrichaceae (Bryophyta) no Brasil
}

\author{
Thaís de Freitas Vaz-Imbassahy, \\ Caio Amitrano de Alencar Imbassahy ${ }^{2} \&$ Denise Pinheiro da Costa ${ }^{3}$
}

\section{Resumo}

(Sinopse de Pilotrichaceae (Bryophyta) no Brasil) A família Pilotrichaceae no Brasil apresenta 11 gêneros e 51 espécies, ocorre principalmente nos biomas Mata Atlântica e Amazônia, com maior riqueza de espécies concentradas nas Regiões Sudeste e Sul. Trinta e quatro táxons são neotropicais e 10 endêmicos do Brasil. Quatro táxons são considerados Vulneráveis, um Em Perigo e dois Criticamente em Perigo no país. Neste estudo foram aceitos os vinte oito sinônimos recentemente realizados no tratamento para o estado do Rio de Janeiro e nas revisões dos gêneros Lepidopilum e Hypnella. Foram estudados materiais tipos de seis espécies. É apresentada uma chave para gêneros e espécies, e para cada táxom são fornecidas informação sobre o tipo, material examinado, distribuição geográfica no Brasil e no mundo, substrato, variação altitudinal, status de conservação dos táxons no país e comentários taxonômicos quando necessários. São apresentadas ao final do trabalho três listas, uma de sinônimos e duas de táxons excluídos. São fornecidas também ilustrações para aqueles táxons que representam novos registros ou que se encontram ameaçados no país ou que não possuem ilustrações. Este estudo permitiu uma redução de $20 \%$ do número total de táxons citados para o Brasil.

Palavras-chave: briófitas, taxonomia, conservação, musgos pleurocárpicos.

\section{Abstract}

(Synopsis of Pilotrichaceae (Bryophyta) from Brasil) The Pilotrichaceae is represented in Brazil by 11 genera and 51 species, occurring mainly in the Atlantic Rain Forest and Amazonia, with the highest richness found in southeastern and southern Brazil. Thirty-four species are neotropical and 10 are endemic to Brazil. Four species are considered vulnerable, one endangered and two critically endangered. In this study 28 synonyms recently reduced in the treatment for Rio de Janeiro state and the taxonomic revisions of Lepidopilum e Hypnella are accepted. Type material of six species were studied. A key for the genera and species is provided, and for each species the following information is given; types, material examined, distributional range, substrate, altitudinal range, conservation status in the country and, when necessary, taxonomic comments. Following the taxonomic treatment three lists are presented, one with synonyms and two with excluded taxa. Illustrations are provided for those species that represents new records, considered threatened or those with no illustrations. This study reduced by $20 \%$ the total number of taxa cited previously for Brazil. Key words: bryophytes, taxonomy, conservation, pleurocarpous mosses.

\section{INTRODUÇÃO}

A família Pilotrichaceae foi criada por Nils Conrad Kindberg (1899) e pertence à ordem Hookeriales, subfamília Hypnelloideae (Buck et al. 2005). Compreende 23 gêneros e cerca de 440 espécies no mundo (Crosby et al. 1999), apresentando-se bem diversificada na América tropical, com 21 gêneros e cerca de 200 espécies (Gradstein et al. 2001), especialmente nas regiões úmidas, bem como na África e Ásia tropicais. Pilotrichaceae caracteriza-se por apresentar os ramos primários rastejantes e os secundários ascendentes ou eretos, costa dupla geralmente bem desenvolvida, presença de hialoderme no caulídio da maior parte dos gêneros, filídios freqüentemente complanados, células variando de isodiamétricas a lineares, lisas ou papilosas, sendo as alares não diferenciadas, e caliptra geralmente pilosa (Buck 1998; Gradstein et al. 2001).

A família apresenta diversos problemas taxonômicos, especialmente no que diz respeito à delimitação de seus gêneros e espécies, o que em parte pode ser explicado pela grande variabilidade dos táxons. Esta variabilidade

Artigo recebido em 05/2008. Aceito para publicação em 07/2008.

${ }^{1}$ Bolsista CNPq (PROTAX), Aluna de doutorado do Programa de Pós-Graduação em Ciências Biológicas (Botânica) Museu Nacional, UFRJ, Quinta da Boa Vista, São Cristóvão, 20940-040, Rio de Janeiro, RJ, Brasil

${ }^{2}$ Professor Substituto do Departamento de Botânica-Instituto de Biologia, UFRJ.

${ }^{3}$ Instituto de Pesquisas Jardim Botânico do Rio de Janeiro, R. Pacheco Leão 915, 22460-030, Rio de Janeiro, RJ, Brasil

${ }^{4}$ Autor para correspondência: vazimbassahy@gmail.com 
levou a descrições de muitas espécies novas no final do século XIX e início do século XX, principalmente por Mitten (1869), Hampe (1872, 1874a, b, 1877, 1879), Müller (1898, 1900), e Brotherus (1900, 1907).

Desde o tratamento clássico de Brotherus (1925), a posição dos gêneros de Pilotrichaceae tem variado no trabalho de diferentes autores (Miller 1971; Crosby 1974; Vitt 1984; Crum 1984; Buck 1987; Whittemore \& Allen 1989; Buck \& Goffinet 2000; Goffinet \& Buck 2004), como apresentado no histórico da família de Vaz-Imbassahy \& Costa (2008a).

No Brasil, a maioria dos trabalhos que tratam Pilotrichaceae (Sehnem 1979; Yano 1981, 1985, 1989, 1995, 1996, 2006; Yano \& Lisboa 1988; Schäfer-Verwimp 1989; Pôrto 1990; Schäfer-Verwimp 1992; Yano \& Mello 1992; Lisboa 1994; Lisboa \& Maciel 1994; Costa \& Yano 1995; Lisboa \& Ilkiu-Borges 1996, 1997; Bastos \& Vilas Bôas-Bastos 1998; Churchill 1998; Oliveira-e-Silva \& Yano 1998, 2000; Lisboa et al. 1998, 1999; Visnadi \& Vital 2000; Yano \& Colletes 2000; Yano \& Costa 2000; Valdevino et al. 2002; Vilas Bôas-Bastos \& Bastos 2002, 2004; Santos \& Lisboa 2003; Yano et al. 2003; Visnadi 2004; Yano \& Bastos 2004; Yano \& Câmara 2004; Yano \& Peralta 2004; Câmara et al. 2005; Costa et al. 2005a, 2005b; Peralta \& Yano 2005; Souza \& Lisboa 2005; Joyce et al. 2006; Ganacevich \& Mello 2006; Genevro et al. 2006; Lisboa et al. 2006; Paixão \& Mello 2006; Peralta \& Yano 2006; Yano \& Peralta, 2006a,b; Yano \& Pôrto 2006; Oliveira \& Alves 2007; Yano \& Peralta 2007) abordam inventários florísticos ou novas ocorrências para o país.

Recentemente estudos de cunho taxonômico com a família Pilotrichaceae foram realizados no Rio de Janeiro, sendo reconhecidos 10 gêneros e 34 espécies (Vaz \& Costa 2006a,b; Vaz-Imbassahy \& Costa 2008a,b). Estes trabalhos demonstram a importância da realização deste tipo de estudo para a contribuição ao conhecimento taxonômico de Pilotrichaceae, uma vez que reduziram em $42 \%$ o número total de táxons registrados para o estado (Vaz-Imbassahy \& Costa 2008a).
O presente estudo tem como objetivo contribuir para o conhecimento da família Pilotrichaceae no Brasil, fornecendo uma sinopse da família para o país, com chave para a identificação dos gêneros e espécies. Além disso, para cada táxon são fornecidos comentários taxonômicos e ecológicos, sua distribuição no Brasil e no mundo, a variação altitudinal no Brasil, análise do status de conservação dos táxons no país e lista de espécies excluídas.

\section{Material e Métodos}

Inicialmente foi elaborada uma lista com 136 táxons de Pilotrichaceae registrados para o Brasil tendo como base Wijk et al. (19591969), os catálogos de Yano (1981, 1989, 1995 , 1996, 2006) e os dados publicados posteriormente a estes (Câmara et al. 2005; Costa et al. 2005a, 2005b; Peralta \& Yano 2005; Souza \& Lisboa 2005; Peralta \& Yano 2006; Yano \& Pôrto 2006; Yano \& Peralta 2007).

Em seguida, foi elaborada a revisão nomenclatural desta lista, com base em Allen (1986), Churchill (1988), Crosby et al. (1999), Vital \& Visnadi (2000), Vaz \& Costa (2006a, b), Vaz-Imbassahy \& Costa (2008a, b e consulta pessoal ao Dr. Steven Paul Churchill do Missouri Botanical Garden, especialista na família. Além disso, foram incluídos os dados obtidos com o estudo das coleções dos seguintes herbários nacionais e estrangeiros: ALCB, H, HRJ, INPA, JE, MG, MO, NY, PACA, PI, RB, RFFP, R, S, SP, TENN, UFP.

A classificação adotada neste trabalho segue Goffinet \& Buck (2004) e os termos utilizados na chave de identificação e comentários seguem Luizi-Ponzo et al. (2006).

Os dados de distribuição geográfica no Brasil e no mundo, variação altitudinal no país e substrato foram obtidos através do estudo das coleções de herbário, complementados com dados da literatura.

A análise do status de conservação das espécies seguiu os critérios estabelecidos por Hallinbäck \& Hodgetts (2000). 
São apresentadas, ao final do trabalho, ilustrações para os táxons que representam novos registros para o Brasil (Lepidopilum erectiusculum e L. pallidonitens), para aqueles que apresentam algum grau de ameaça no país (Brymela fluminensis, Cyclodyction olfersianum, Hypnella punctata, Thamniopsis pendula, T. purpureophylla e Trachyxiphium variabile), que não apresentam ilustrações em outros trabalhos (Cyclodictyon marginatum) ou que apresentam restrição de habitat (Philophyllum tenuifolium). Como não foi possível examinar material de Hypnella punctata, a ilustração foi redesenhada de Allen (1986).

\section{Resultados}

Eram citadas na literatura para o Brasil 14 gêneros e 136 espécies de Pilotrichaceae
(Wijk et al. 1959-1969; Yano 1981, 1989, 1995, 1996, 2006). Após a revisão nomenclatural da lista e do estudo das coleções de diferentes herbários foi possível reduzir em $66 \%$ o número total de táxons registrados para o país. Cinquenta e oito espécies foram excluídas por serem consideradas errôneas ou duvidosas e 28 foram reduzidas a sinônimos por diferentes autores (Florschütz-de Waard 1986; Churchill 1988; Churchill \& Fuentes 2005; Vaz \& Costa 2006a, b; Vaz-Imbassahy \& Costa 2008a, b). Duas espécies representam novas ocorrências para o país: Lepidopilum erectiusculum e Lepidopilum pallidonitens. Assim, neste estudo são reconhecidos para o Brasil 11 gêneros e 51 espécies de Pilotrichaceae ocorrendo em 23 estados do país (Tab. 1), representando $35 \%$ do total de espécies desta família registrada para a América tropical e 11\% para o mundo.

\section{Chave para gêneros e espécies de Pilotrichaceae do Brasil}

1. Filídios sem costa ou com costa curta e bifurcada (ca. 1/6 do comprimento do filídio) ou ligeiramente alongada e simples. Plantas freqüentemente encontradas em tanques de bromélias Philophyllum tenuifolium

1'. Filídios sempre com costa, costa dupla, curta ou longa.

2. Células da lâmina papilosas.

3. Células da lâmina uni- ou pluripapilosas, papilas sobre o lúmen celular.

4. Células da lâmina unipapilosas (raramente com duas papilas), isodiamétricas ...

5. Callicostella p.p.

5. Margem do filídio sem dentes inflados; costa não projetada ....... . martiana

5'. Margem do filídio com dentes inflados; costa projetada, denteada no ápice.

6. Filídios laterais e dorsais/ventrais diferenciados pela forma ou simetria.

7. Filídios diferenciados por simetria, os laterais assimétricos com ápice rotundo e dorsais/ventrais simétricos com ápice variando de agudo, rotundo a cuspidado; margem levemente serrulada na metade superior do filídio; células da lâmina raramente papilosas; seta rugosa

C. pallida

7'. Filídios diferenciados por forma, laterais oblongos com ápice rotundo a truncado ou agudo a mucronado e dorsais/ventrais ovados com ápice obtuso; margem serreada na metade superior do filídio; células da lâmina papilosas, podendo as basais serem lisas; seta lisa.

8. Filídios laterais com ápice rotundo a truncado; costa convergente no ápice; seta lisa

C. apophysata

8'. Filídios laterais com ápice agudo a mucronado; costa paralela ou divergente no ápice; seta rugosa C. ciliata

6'. Filídios laterais e dorsais/ventrais similares. 
9. Filídios oblongos; costa alcançando ca. 5/6 do comprimento do filídio, ápice denteado por 1-2 dentes ........................................................ C. microcarpa

9'. Filídios ovados a oblongo-ovados; costa alcançando ca. 9/10 do comprimento do filídio, ápice denteado por 2-4(-6) dentes ..................................... . depressa

4'. Células da lâmina pluripapilosas, alongadas. ...................................... 10. Hypnella

10. Filídios côncavos, ápice cuculado, costa alcançando ca. 1/4-1/2 do comprimento, células da lâmina com 3-7 papilas pedunculado-estreladas ......... H. pallescens

10'. Filídios planos, ápice longo-aristado ou agudo, costa alcançando ca. 3/5-4/5 do comprimento, células da lâmina com 2-5 papilas simples.

11. Ápice do filídio agudo, margem levemente diferenciada por células lisas e alongadas

H. punctata

11'. Ápice do filídio longo-aristado, margem não diferenciada

H. pilifera

3'. Células da lâmina unipapilosas, papilas no ângulo apical.

12. Células da lamina alongadas, $4-8$ vezes mais longas que largas.

13. Dentes marginais do filídio usualmente simples, não inflados

14. Brymela

14. Filídios lanceolados, planos, falcados, não ondulados, com ápice longoacuminado

B. fluminensis

14'. Filídios oblongos a oblongo-lanceolados, freqüentemente côncavos, não falcados, ondulados, com ápice obtuso ou mais comumente agudo

B. parkeriana

13'. Dentes marginais do filí́dio freqüentemente bífidos, inflados

15. Trachyxiphium p.p.

15. Costa alcançando até $4 / 5$ do comprimento do filídio, ápice projetado, freqüentemente cristado.

16. Filídios ligeiramente diferenciados, os laterais assimétricos e os dorsais/ ventrais simétricos; margem fortemente serreada, com dentes inflados e bífidos; costa com ápice fortemente denteado e cristado

T. guadalupense

16'. Filídios não diferenciados, os laterais e os dorsais/ventrais similares; margem serrulada a serreada, ocasionalmente com dentes inflados e bífidos; costa com ápice levemente denteado, nunca cristado

T. variabile

15'. Costa ultrapassando 4/5 do comprimento do filídio, ápice não projetado, nunca cristado.

T. aduncum

12'. Células da lâmina curtas (2-4 vezes mais longas que largas) ou isodiamétricas.

17. Costa inconspícua, ca. $1 / 2$ do comprimento do filídio; seta lisa

Helicoblepharum brasiliense

17'. Costa conspícua, 2/3-4/5 do comprimento do filídio; seta lisa ou ocasionalmente rugosa

18. Pilotrichum

18. Filídios planos a ligeiramente côncavos; costa cristada, crista alta a baixa, ápice formando longo espinho; propágulos no espinho da costa

P. bipinnatum

18'. Filídios côncavos; costa cristada ou não, crista baixa, com ápice ligeiramente projetado; propágulos na base da costa

P. evanescens

2'. Células da lâmina lisas ou raramente papilosas.

19. Filídios bordeados por células mais estreitas e alongadas do que as da lâmina.

20. Dentes marginais do filídio freqüentemente inflados, algumas vezes bífidos 
21. Filídios do caulídio e dos ramos diferenciados

T. cruegeriana

21'. Filídios do caulídio e dos ramos não diferenciados.

22. Filídios laterais assimétricos e dorsais/ventrais simétricos, levemente ou não ondulados.

23. Filídios oblongo-ovados a elípticos; células da lâmina romboidais ( \pm 1-2:1).

T. incurva

23'. Filídios lanceolados a oblongo-laceolados; células da lâmina romboidais a longo-romboidais $( \pm 4-6: 1)$ T. langsdorffii

22'. Filídios laterais e dorsais/ventrais não diferenciados, similares, fortemente ondulados T. undata

20 '. Dentes marginais do filídio não inflados ou bífidos.

24. Células da lâmina laxas, curto-hexagonais a romboidais; seta lisa, cápsula pendente, dentes do exóstoma estriados transversalmente 25. Cyclodictyon

25. Margem composta por 2 ou mais fileiras de células mais estreitas que as da lâmina.

26. Filídios oblongos a oblongo-ovados, ápice abruptamente acuminado a apiculado; borda composta por 2-3 fileiras de células mais estreitas

C. albicans

26’ . Filídios oblongos, ápice cuspidado; borda composta por 3 fileiras de células mais estreitas

C. marginatum

25'. Margem composta por 1-2 fileiras de células mais estreitas que as da lâmina.

27. Ápice da costa projetado na superfície dorsal.

28. Filídios ovados a oblongo-ovados

C. limbatum

28'. Filídios oblongos

C. olfersianum

$27^{\prime}$. Ápice da costa não projetado na superfície dorsal

C. varians

24'. Células da lâmina lineares ou longo-romboidais; seta papilosa ou mais freqüentemente espinhosa, dentes do exóstoma papilosos 29.Lepidopilum p.p.

29. Margem composta por 2-5 fileiras de células lineares e mais estreitas que as da lâmina

L. tortifolium

29’. Margem composta por 1-4(5) fileiras de células lineares e mais estreitas que as da lâmina.

30. Filídios oblongo-obovados, ápice agudo a rotundo-apiculado ... L. surinamense 30’. Filídios ovado-lanceolados a ovado-oblongos, ápice curto a longo-acuminado

L. polytrichoides

19'. Filídios não bordeados, células marginais similares às da lâmina ou gradualmente diferenciadas em direção à margem.

31. Células da lâmina curtas, isodiamétricas a curto-oblongas, 2-3:1 .... 32. Callicostella p.p.

32. Filídios oblongos a oblongo-ovados, ápice rotundo; costa convergente no ápice; seta lisa

C. merkelii

32'. Filídios oblongos, ápice truncado a cuspidado, algumas vezes agudo, e menos frequentemente longo-acuminado; costa paralela no ápice; seta rugosa ou papilosa

C. rufescens

31'. Células da lâmina alongadas, (4-)5-10 ou mais:1.

33. Plantas freqüentemente epífitas, ramos secundários ascendentes e freqüentemente perpendiculares ao substrato; seta lisa a mais comumente papilosa ou espinhosa, dentes do exóstoma papilosos ou estriados transversalmente. 
34. Exóstoma papiloso; seta papilosa ou espinhosa 35. Lepidopilum p.p.

35. Filídios laterais e dorsais/ventrais diferenciados, os laterais assimétricos e os dorsais/ventrais simétricos.

36. Filídios ovados a oblongo-lanceolados, freqüentemente 2-3 vezes mais longos que largos.

37. Filídios ovados

L. ovalifolium

37'. Filídios oblongo-lanceolados.

38. Ápice do filídio agudo, podendo apresentar propágulos, e células romboidais L. cubense

38'. Ápice do filídio acuminado, sem propágulos e células linear-romboidais.

39. Filídios laterais fortemente sigmóides; margem dos filídios serreada no ápice e serrulada em direção à base

L. scabrisetum

39'. Filídios laterais não sigmóides; margem dos filídios serrulada no ápice e inteira a sinuada em direção à base

L. caudicaule

36'. Filídios lanceolados, frequientemente 4-5 vezes mais longos que largos.

40. Ápice do filídio acuminado a longo-acuminado.

41. Filídios ovado-lanceolados, ápice acuminado, células romboidais

L. muelleri

41'. Filídios oblongo-lanceolados, ápice longo-acuminado, células lineares

L. subsubulatum

40’. Ápice do filí́dio curto-acuminado

L. brevipes

35'. Filídios laterais e dorsais/ventrais não diferenciados, todos similares e simétricos.

42. Filídios oblongos a ovado-oblongos.

43. Filídios ovado-oblongos, ondulados, ápice agudo e frequentemente com propágulos na base L. affine

43'. Filídios oblongos, não ondulados, ápice mucronado a cuspidado ou longo-cuspidado L. pallidonitens

42'. Filídios lanceolados a oblongo-lanceolados.

44. Margem do filídio fortemente serreada e com dentes projetados

L. erectiusculum

44'. Margem do filídio serrulada a levemente serreada, sem dentes projetados

L. longifolium

34'. Exóstoma estriado transversalmente; seta lisa ou, muito raramente, papilosa

45. Lepidopilidium

45. Filídios ligeiramente diferenciados, os laterais assimétricos e os dorsais/ventrais simétricos; margem ligeiramente bordeada por células mais estreitas que as da lâmina.

46. Filídios oblongos a oblongo-ovados, com ápice obtuso

46'. Filídios ovados, com ápice acuminado

L. portoricense

45'. Filídios não diferenciados, todos simétricos e similares; margem não bordeada.

47. Ápice do filídio agudo; margem serreada no ápice e inteira em direção à base; costa alcançando ca. $1 / 2$ do comprimento do filídio

L. brevisetum

47'. Ápice do filídio acuminado a longo-acuminado; margem serrulada a serreada no ápice e serrulada em direção à base; costa alcançando $1 / 2-2 / 3$ do comprimento do filídio.

48. Ápice do filídio longo-acuminado; margem serreada no ápice; costa alcançando $1 / 2$ do comprimento do filídio; células apicais da lâmina lineares ... L. aureo-purpurem

48'. Ápice do filí́dio acuminado; margem serrulada no ápice; costa alcançando 1/22/3 do comprimento do filídio; células apicais da lâmina linear-romboidais 
33'. Plantas freqüentemente terrestres ou saprófitas, ocasionalmente em troncos vivos de árvore; seta lisa, dentes do exóstoma estriado transversalmente.

49. Ramos em secção transversal com hialoderme evidente; células basais da lâmina diferentes das apicais (areolação heterogênea) 50. Thamniopsis p.p.

50. Margem do filídio inteira, ápice obtuso T. pendula 50'. Margem do filídio serrulada, ápice aristado .... T. purpureophylla

49'. Ramos em secção transversal sem hialoderme; células basais da lâmina similares às apicais (areolação homogênea) Trachyxiphium heteroicum

1. Brymela fluminensis (Hampe) W.R. Buck, Brittonia 39: 217. 1987. Tipo: BRASIL. RIO DE JANEIRO: A.F.M. Glaziou 11727 (holótipo, BM; isótipo, NY). Fig. 1 a-h Material examinado: BRASIL. RIO DE JANEIRO: Itatiaia, Cachoeira do Maromba, 27.V.1927, $P$. Occhioni s.n. (RB 156664).

Espécie endêmica do Brasil e restrita à Mata Atlântica, encontrada no ES, RJ, SP, PR e RS, ocorrendo sobre rochas úmidas, 8002500 m. Status de conservação: Vulnerável (VU).

Embora tenham sido realizados esforços de coleta no estado do Rio de Janeiro incluindo a localidade do único material examinado, e tenham sido visitados os principais herbários do país, não foi encontrado nenhum outro material coletado há menos de 20 anos.

2. Brymela parkeriana (Hook. \& Grevile) W.R. Buck, Brittonia 39: 218. 1987. Tipo: GUIANA. DEMERARA: T. Parker s.n. (holótipo, BM).

Material examinado: BRASIL. AMAZONAS: Manaus, 1.VIII.1974, D. V. Vital 4286 (SP); estrada Manaus-Itacoatiara, Reserva Florestal Ducke, 28.I.1977, R. C. Lisboa 256 (MG); Serra do Curicuriari, 10.VI.1979, O. Yano 1869 (INPA); entre Manaus e São Gabriel, ao longo do Rio Negro, 912.VII.1979, W. R. Buck 2445 (TENN).

Ocorre no norte da América do Sul e Barbados e no Brasil é restrita a região Amazônica (AM, PA e MT), crescendo sobre troncos, ramos e folhas de árvores e arbustos, lianas e cupinzeiros sobre árvores, 0-250 m. Status de conservação: Baixo risco (LC).
3. Callicostella apophysata (Hampe) A. Jaeger, Ber. Thätigk. St. Gallischen Naturwiss. Ges. 1875-76: 352. 1877. Tipo: BRASIL. RIO DE JANEIRO: A.F.M. Glaziou, ex Herb. Hampe $n^{\circ} 7199$ (holótipo, BM!).

Material examinado: BRASIL. RIO DE JANEIRO: Magé, Distrito de Santo Aleixo, RPPN El Nagual, 4.VIII.2005, N. D. Santos \& D. P. Costa 333 (RB); 5.VIII.2005, N. D. Santos \& D. P. Costa 363 (RB).

Endêmica do Brasil, conhecida para GO e RJ, ocorrendo sobre rochas e troncos em decomposição, ao longo de cursos de água, 200-400 m. Status de conservação: Dados deficientes (DD).

4. Callicostella ciliata (Schimp.) A. Jaeger, Ber. Thätigk. St. Gallischen Naturwiss. Ges. 1875-76: 355. 1877. Tipo: MÉXICO. MIRADOR: F.M. Liebmann (holótipo, C). Material examinado: BRASIL. SÃO PAULO: Ilha Bela, 31.XII.1982, O. Yano 5164 (SP).

Apresenta distribuição Neotropical. No Brasil é conhecida para o MT e SP, ocorrendo sobre troncos em decomposição e pedra de rio, podendo estar submersa, 0-800 m. Status de conservação: Dados deficientes (DD).

5. Callicostella depressa (Hedw.) A. Jaeger, Ber. Thätigk. St. Gallischen Naturwiss. Ges. 1875-76: 352. 1877. Tipo: JAMAICA. 17831787, O. Swartz s.n. (holótipo, NY).

Material examinado: BRASIL. ACRE: Juruá, Rio Juruá, V.1901, E. Ule s.n. (MG 20106); Reserva Indígena da Praia do Carapanã, colocação Macuripe, 20.XI.1995, D.P. Costa et al. 2708 (RB). AMAZONAS: estrada entre Humaitá e Porto Velho, 4.V.1982, A. 
Fife et al. 4040 (INPA); São Gabriel da Cachoeira, 18.VII.1977, O. Yano 2037 (SP). MATO GROSSO: Chapada dos Guimarães, 21.III.1983, R. C. L. Lisboa et al. 3180 (MG). MINAS GERAIS: Padre Paraíso, 29.III.1976, Vital 5895(SP). PARÁ: Marabá, Serra Norte (Carajás), 17.III.1985, R. Secco et al. 494 (MG); Serra do Cachimbo, 10-15.V.1983, W.D. Reese 16714 (INPA). RIODEJANEIRO: Rio de Janeiro, PARNATijuca, Rio dos Macacos, 13.IX.1984, D. P. Costa 114 (RB); Santa Maria Madalena, trilha para o Pico do Desengano, $T$. F. Vaz-Imbassahy et al. 142 (RB). RONDÔNIA: Alvorada, Silva \& C. S. Rosário 6409 (MG); Vilhena, estrada para Aripuanã, 21.V.1984, C. S. Rosário et al. 468(MG). RORAIMA: BR 174 (Manaus-Venezuela), 29.XI.1977, W. R. Buck et al. 1947a (INPA). SÃO PAULO: Cubatão, 18.VI.1986, D. M. Vital 13819 (SP); Peruíbe, 3.VII.1988, O. Yano et al. 11577 (SP).

Apresenta distribuição Neotropical e no Brasil é conhecida para RR, RO, AC, AM, PA, AL, MT e RJ, sendo aqui ampliada a sua distribuição para a Região Sudeste, estados de MG e SP. Ocorre sobre troncos em decomposição, solo e pedras, mais raramente sobre troncos de árvore, 0-800 m. Status de conservação: Baixo risco (LC).

6. Callicostella martiana (Hornsch.) A. Jaeger, Ber. Thätigk. St. Gallischen Naturwiss. Ges. 1875-76: 351. 1877. Tipo: BRASIL. BAHIA: Rio São Francisco, próximo a Juazeiro, C.F.P. Martius s.n. (holótipo, BM).

Material examinado: BRASIL. RIO DE JANEIRO: Parati, estrada para Parati-Mirim, 22.X.1990, D.P. Costa et al. 1315 (RB).

Endêmica do Brasil, conhecida para BA, MT, MG, RJ, PR, SCe RS, ocorrendo sobre troncos em decomposição, solo ou pedras, freqüientemente associada a cursos de água, 0-1000 m. Status de conservação: Baixo risco (LC).

7. Callicostella merkelii (Hornsch.) A. Jaeger, Ber. Thätigk. St. Gallischen Naturwiss. Ges. 1875-76: 356 (1877). Tipo: BRASIL. RIO DE JANEIRO: F. Merkel s.n. (holótipo, BM). Material examinado: BRASIL. ACRE: Juruá, Rio Juruá, VI.1901, E. Ule s.n. (MG20107). AMAZONAS: Lábrea, Bacia do Rio Purus, 31.X.1969, G. Prance et al. 8129 (INPA). PERNAMBUCO: Bonito, Reserva Ecológica, 28.IV.1995, s. col. (UFP20255); Quipapá, 2.IX.1980, O. Yano et al. 2863 (SP). RIO DE
JANEIRO: Angra dos Reis, Ilha Grande, trilha para Parnaioca, 16.V.1995, M. I. M. N. Oliveira-e-Silva 4161 (HRJ); Campos dos Goytacazes, Fazenda Mocotó, T.F. Vaz-Imbassahy et al. 179 (RB); Mangaratiba, km 54 da rodovia Rio-Santos, Reserva Ecológica Rio das Pedras, 5.VIII.1993, M. I. M. N. Oliveira-eSilva 596 (HRJ); Rio de Janeiro, PARNA Tijuca, trilha para Cachoeira das Almas, T. F. Vaz-Imbassahy et al. 108 (RB); Santa Maria Madalena, Morumbeca do Imbé, T. F. Vaz-Imbassahy et al. 162 (R).

Apresenta distribuição Neotropical e no Brasil é conhecida para as florestas Amazônica e Atlântica, estados de RR, AP, AC, PA, MG, RJ, SP e SC, sendo aqui citada pela primeira vez para AM e PE. Ocorre sobre solo, pedras e troncos em decomposição, freqüentemente associados a cursos de água, 0-800 m. Status de conservação: Baixo risco (LC).

8. Callicostella microcarpa Ångstr., Öfvers. Förh. Kongl. Svenska Vetensk.-Akad. 33(4): 27. 1876. Tipo: BRASIL. MINAS GERAIS: C.F.P. Martius s.n. (holótipo, BM ?).

Material examinado: BRASIL. RIO DE JANEIRO: Petrópolis, Serra da Estrela, trilha para o Morro do Castelo, T. F. Vaz-Imbassahy et al. 87 (R). MINAS GERAIS: Caldas, J. F. Widgren s.n. (SP 113421); C. F. Hornschuch \& C. F. P. Matius s.n. (SP 113414). SÃO PAULO: 4.II.1920, A. Gerht 39 (SP).

Apresenta distribuição Neotropical e no Brasil é conhecida para as florestas Amazônica e Atlântica, estados de RR, AM, PA, MG, RJ, $\mathrm{SP}$ e SC. Ocorre sobre troncos em decomposição, solo e pedras, freqüentemente associada a cursos de água, 0-850 m. Status de conservação: Baixo risco (LC).

Pode ser reconhecida pelo seu tamanho reduzido (0,8-1,0 $\mathrm{mm}$ de largura), e filídios variando entre $0,5-0,8 \mathrm{~mm}$ de comprimento e $0,1-0,3 \mathrm{~mm}$ de largura.

9. Callicostella pallida (Hornsch.) Ångstr., Öfvers. Förh. Kongl. Svenska Vetensk.-Akad. 33(4): 27. 1876. Tipo: BRASIL. AMAZONAS: Segundo afluente do Rio Amazonas, C.F.P. Martius s.n.; MINAS GERAIS: Vila Rica, C.F.P. Martius s.n.; RIO DE JANEIRO: Tijuca, H.C. Beyrich \& J.F.M. Olfers s.n. (síntipos, BM). 


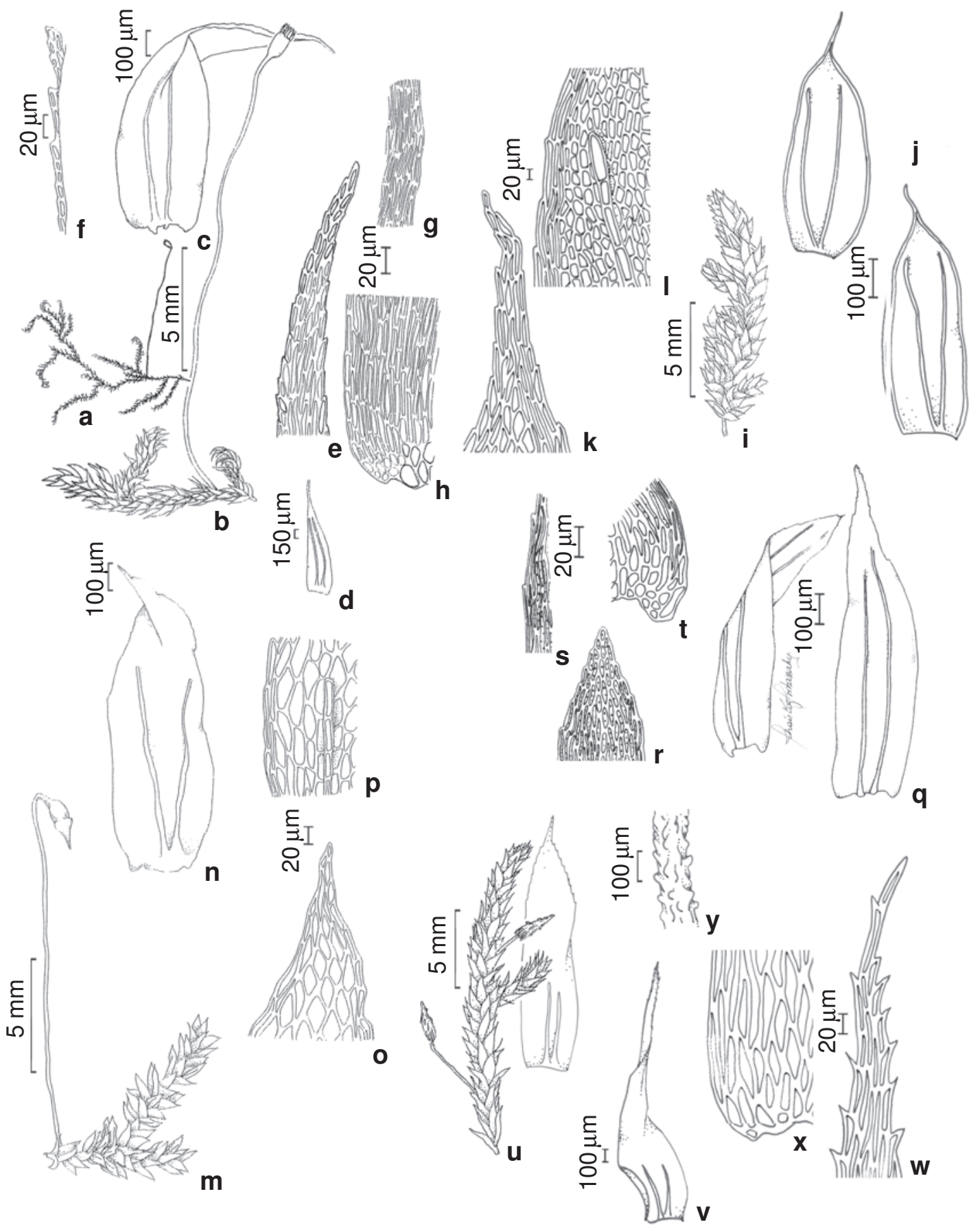

Figura 1 - a-h. Brymela fluminensis (Hampe) W. R. Buck - a. hábito; b. detalhe do gametófito com esporófito; c. filídio; d. forma do filídio; e. células do ápice do filídio; f. detalhe do ápice da costa; g. células da margem do filídio; h. células da base do filídio (Occhioni s.n. RB 156664). i-l. Cyclodictyon marginatum (Hook. \& Wilson) O. Kuntze - i. detalhe do gametófito; j. filídios; k. células do ápice do filídio; l. detalhe do ápice da costa e células da margem do filídio (VazImbassahy 156). m-p. C. olfersianum (Hornsch.) O. Kuntze - m. detalhe do gametófito com esporófito; n. filídio; o. células do ápice do filídio; p. detalhe do ápice da costa e células da margem do filídio (Costa 506). q-t. Hypnella punctata Broth. - q. filídios; r. células do ápice do filídio; s. células da margem do filídio; t. células da base do filídio (redesenhado de Allen, 1986). u-y. Lepidopilum erectiusculum (Taylor) Mitt. - u. detalhe do gametófito com esporófito; v. filídios; w. células do ápice do filídio; x. células da base do filídio; y. detalhe da seta papilosa (Prance 12551). 
Material examinado: BRASIL.ACRE: Cruzeiro do Sul, Porangaba, 16.V.1971, Maas et al. P13042 (INPA). AMAPÁ: Macapá, Rio Araguari, VIII.1983, C.S. Rosário 230 (MG). AMAZONAS: Fortaleza, Rio Purciari, 1.VII.1971, G. Prance et al. 13864 (MG). BAHIA: Eunápolis, Estação Veracruz, 11.VI.1999, S. Vilas Bôas-Bastos \& C. J. Bastos 805 (ALCB). PARÁ: Belém, 19.X.1982, R. C. L. Lisboa et al. 436(SP); Ilha do Mosqueiro, 3.X.1967, P. Cavalcante 1828 (MG). MATOGROSSO:Aripuanã, 27.IX.1975, R. C. L. Lisboa et al. 342 (MG); Barra do Garça, 20.V.1968, D. M. Vital 1345 (SP). MATO GROSSO DO SUL: Corumbá, 2.XI.1993, O. Yano et al. 21096 (SP). PERNAMBUCO: Rio Formoso, 16.VII.1985, K. C. Pôrto 1178 (UFP); São Lourenço da Mata, 4.II.1988, O. Yano \& G. Mariz 11265 (SP). RIO DE JANEIRO: Angra dos Reis, 19.VII.1966, D.M. Vital 945 (SP); Mangaratiba, km 54 da rodovia Rio-Santos, Reserva Ecológica Rio das Pedras, 11.II.1993, M. I. M. N. Oliveira-e-Silva 181-a (HRJ); Petrópolis, Serra da Estrela, trilha para o Morro do Castelo, T. F. Vaz-Imbassahy et al. 97 (RB); Rio de Janeiro, PARNA Tijuca, 10.IX.1983, D. P. Costa 33 (RB); Santa Maria Madalena, trilha para Morumbeca do Imbé, T. F. Vaz-Imbassahy et al. 171 (R). RORAIMA: vizinhança de Auaris, 23.VII.1974, G. Prance 21341 (MG). RONDÔNIA: Jaru, 2.X.1986, D. M. Vital 14047 (SP); Ouro Preto do Oeste, 3.X.1986, D. M. Vital 14112 (SP); Presidente Médici, R. C. L. Lisboa et al. 3375 (MG). SÃO PAULO: Cananéia, 27.VIII.1997, O. Yano \& G. A. Lindenberg 24919 (SP); Cubatão, 18.IV.1993, O. Yano et al. 18790 (SP); Mogi das Cruzes, 26.VII.1961, G. Eiten \& L. T. Eiten 2502 (SP); Mongaguá, 22.IV.1993, O. Yano \& M. Marcelli 18948 (SP); Peruíbe, 23.VII.1988, O. Yano \& M. Marcelli 11695 (SP); Santos, XII.1920, J. Melzer s.n. (SP88574).

Apresenta distribuição Neotropical e no Brasil está amplamente distribuída (RR, RO, AP, AC, AM, PA, PE, TO, CE, AL, SE, BA, GO, MT, MS, MG, ES, RJ, SP, PR, SC e RS), ocorrendo sobre troncos e raízes vivos, troncos em decomposição e pedras, freqüentemente associada a cursos de água, 0-1300 m. Status de conservação: Baixo risco (LC).

10. Callicostella rufescens (Mitt.) A. Jaeger, Ber. Thätigk. St. Gallischen Naturwiss. Ges. 1875-76: 355. 1877. Tipo: BRASIL. PARÁ: Rio Amazonas, R. Spruce 629 (holótipo, BM). Material examinado: BRASIL. AMAZONAS: Barcelos, Serra do Aracá, III.1984, C. S. Rosário 292 (MG). PERNAMBUCO: Bonito, Reserva Ecológica,
28.IV.1995, K. C. Pôrto \& O. Yano s.n. (UFP20118); Brejo Madre de Deus, Bituri Grande, 28.V.1992, J.A. Valdevino s.n. (UFP 8484); Cabo, 6.IV.2000, S.R. Germano s.n. (UFP 32912); Gurjaú, Mata do Macaco, 18.IX.1995, P. S. A. Sá \& S.R. Germano s.n. (UFP 11307); Rio Formoso, 18.VI.1985, K. C. Pôrto 1094 (UFP); Timbaúba, Engenho Água Azul, 6.V.1993, S. R. Germano \& P. S. A. Sá s.n. (UFP 8726). RIO DE JANEIRO: Parati, trilha do Corisco para Rasa, 13.XI.1990, D. P. Costa et al. 1407 (RB).

É Neotropical e no Brasil apresenta distribuição disjunta entre as florestas Amazônica e Atlântica, estados do AM, PA e RJ, sendo aqui citada pela primeira vez para PE. Cresce sobre pedras, troncos em decomposição e, menos freqüentemente, solo e lianas, 0-200 m. Status de conservação: Baixo risco (LC).

11. Cyclodictyon albicans (Hedw.) O. Kuntze, Revis. Gen. Pl. 2: 835. 1891. Tipo: JAMAICA. O. Swartz s.n. (holótipo, G). Material seleceionado: BRASIL. CEARÁ: Moranguape, 13.X.1993, O. Yano et al. 20703 (SP). MATO GROSSO DO SUL: Corumbá, 2.XI.1993, O. Yano et al. 21097 (SP). MINAS GERAIS: Itamonte, 4.VII.1991, D. M. Vital \& W.R. Buck 19418 (SP). PARANÁ: Foz do Iguaçu, 23.IX.1984, D.M. Vital \& W. R. Buck 12084 (SP); Guaraniaçú, 14.III.1976, D. M. Vital 5784 (SP). PERNAMBUCO: Inajá, 6.IX.1980, O. Yano \& D. Andrade-Lima 2954 (SP); Triunfo, 7.IX.1980, O. Yano \& D. Andrade-Lima 3001 (SP). RIO DE JANEIRO: Nova Friburgo, Pico da Caledônia, 4.V.1988, D. P. Costa et al. 661 (RB); Petrópolis, Serra da Estrela, Estrada Velha, T. F. VazImbassahy et al. 45 (RB); Santa Maria Madalena, trilha para o Pico do Desengano, T. F. Vaz-Imbassahy et al. 145 (R). RIO GRANDE DO SUL: Dois Irmãos, Morro Dois Irmãos, XI.1971, A. Sehnem 11902 (RB); Montenegro, Linha São Pedro, 11.VI.1946, A. Sehnem 399 (RB). SÃO PAULO: Águas da Prata, 17.III.1983, O. Yano 6140 (SP); Cunha, 9.IX.1984, D. M. Vital \& W. R. Buck 11472 (SP); Eldorado, 29.IX.1984, D. M. Vital \& W. R. Buck 12489 (SP); Guarujá, 13.III.2005, D. F. Peralta 2696 (SP); Iporanga, 29.IX.1984, D. M. Vital \& W. R. Buck 12597 (SP); Restinga, 26.VIII.1998, D. M. Vital s.n. (SP388543); São Paulo, 21.V.1974, O. Yano 283 (SP); Ubatuba, 22.XI.2003, D. F. Peralta et al. 1606 (SP). Apresenta distribuição Neotropical e no Brasil é conhecida para CE, MT, MS, MG, RJ, PR e RS, sendo aqui citada pela primeira 
vez para PE e SP. Ocorre sobre pedras úmidas, solo, troncos vivos e em decomposição, freqüientemente associada a cursos de água, 0-2400 m. Status de conservação: Baixo risco (LC).

12. Cyclodictyon limbatum (Hampe) O. Kuntze, Revis. Gen. Pl. 2: 835. 1891. Tipo: BRASIL. RIO DE JANEIRO: A.F.M. Glaziou 7221 (holótipo, MANCH).

Material examinado: BRASIL. RIO DE JANEIRO: Petrópolis, 16.II.1924, M. C. V. Bandeira s.n. (RB 174403). RIO GRANDE DO SUL: Bom Jesus, Arroio das Capoeiras, 15.I.1942, A. Sehnem 292 (PACA); São Leopoldo, Horto Florestal, 28.X.1941, A. Sehnem 203 (PACA). SANTACATARINA: Lages, 10.I.1951, A. Sehnem 5433a (PACA). SÃO PAULO: São Paulo, 9.IV.1974, O. Yano 184 (SP).

Apresenta distribuição Neotropical e no Brasil encontra-se restrita à Mata Atlântica, sendo conhecida para os estados das Regiões Sudeste e Sul (RJ, SP, PR, SC e RS). Ocorre sobre solo úmido, pedras, troncos em decomposição, frequientemente associada a cursos de água, 0-1200 m. Status de conservação: Baixo risco (LC).

13. Cyclodictyon marginatum (Hook. \& Wilson) O. Kuntze, Revis. Gen. Pl. 2: 835. 1891. Tipo: BRASIL. MINAS GERAIS: Piedade, C.A. Gardner 87 (holótipo, BM). $\quad$ Fig. 1 i-1 Material examinado: BRASIL. MINAS GERAIS: Lima Duarte, 9.VIII.1993, O. Yano \& M. Marcelli 20369 (SP). RIO DE JANEIRO: Teresópolis, Pedra do Sino, 25.VII.1990, A. Schäfer-Verwimp \& I. Verwimp 13124 (SP, como C. mollicullum); Santa Maria Madalena, P.E. Desengano, base da Pedra do Desengano, 15.V.2007, T. F. Vaz-Imbassahy et al. 156 (RB).

Endêmica do Brasil, conhecida para as Regiões Sudeste e Sul, estados de MG, SP, PR e RS, sendo aqui citada para o RJ. Ocorre sobre pedras ao longo de cursos de água, solo e troncos em decomposição, 750-1720 m. Status de conservação: Baixo risco (LC).

Diferencia-se das congêneres pela sua coloração castanha, filídios com ápice aristado e células da lâmina muito pequenas ( 14 x $35-$ $47 \mathrm{~mm})$.
14. Cyclodictyon olfersianum (Hornsch.) $\mathrm{O}$. Kuntze, Revis. Gen. Pl. 2: 835. 1891. Tipo: BRASIL. RIO DE JANEIRO: Tijuca, I.F.W. Olfers s.n.; ibidem F. Sellow s.n. (síntipos, $\mathrm{BM})$.

Fig. $1 \mathrm{~m}-\mathrm{p}$ Material examinado: BRASIL. MINAS GERAIS: Fazenda Bom Destino, 22.II.1924, M C. V. Bandeira s.n. (HRJ). RIO DE JANEIRO: Nova Friburgo, Estrada de Vargem Alta para Friburgo, 11.XII.1987, D. P. Costa et al. 506 (RB). SÃO PAULO: Itaperica da Serra, 24.VI.1965, G. Eiten \& R. Godland 6315 (SP).

Ocorre nas Antilhas e no Brasil é conhecida para os estados de MG, RJ, SP, PR, SC e RS, crescendo sobre troncos de árvore e pedras, freqüentemente associada a cursos de água, 0 1100 m. Status de conservação: Vulnerável (VU). Apresenta distribuição restrita às formações de Mata Atlântica, de Terras Baixas, Submontana e Montana, do sudeste e sul do país, e apesar dos esforços de coleta realizados nos últimos anos no Rio de Janeiro, e do estudo das coleções dos principais herbários dessas regiões, o táxon não é recoletado há mais de 20 anos.

15. Cyclodictyon varians (Sull.) O. Kuntze, Revis. Gen. Pl. 2: 835. 1891. Tipo: CUBA. W. Wright s.n. (holótipo, FH).

Material examinado: BRASIL. PARANÁ: Foz do Iguaçu, 23.IX.1984, D. M. Vital \& W. R. Buck 12094 (SP). RIO DE JANEIRO: Mangaratiba, km 54 da Rodovia Rio-Santos, Reserva Ecológica Rio das Pedras, 25.III.1993, M. I. M. N. Oliveira-e-Silva 234 (HRJ); Petrópolis, Serra da Estrela, Estrada Velha, 19.VII.2006, T. F. Vaz-Imbassahy et al. 46 (R).

Apresenta distribuição Neotropical, alcançando o sul dos Estados Unidos, e no Brasil é conhecida para AM, MS, RJ e SP, sendo aqui citada pela primeira vez para o PR. Ocorre sobre troncos em decomposição, pedras e raízes de árvore, freqüentemente associada a cursos de água, $0-500 \mathrm{~m}$. Status de conservação: Baixo risco (LC).

16. Helicoblepharum brasiliense Herzog, Arch. Bot. Est. São Paulo 1(2): 83. 1925. Tipo: BRASIL. MINAS GERAIS: Passa Quatro, III.1921, J.F. Zikán 232 (holótipo, SP!).

Endêmica do Brasil, ocorrendo no estado de MG, sem informação sobre a localidade, 
substrato e altitude. Status de conservação: Dados deficientes (DD).

Foi incluída em dados deficientes, visto que o conhecimento da brioflora do estado de Minas Gerais está quase que restrito aos trabalhos de Ångström (1876) e o único exemplar conhecido é o tipo, coletado há mais de 80 anos.

Apresenta filídios lanceolados a ovados, com células da lâmina oblongas a romboidais, com papila no ângulo apical e costa inconspícua divergente.

17. Hypnella pallescens (Hook.) A. Jaeger, Ber. Thätigk. St. Gallischen Naturwiss. Ges. 1875-76: 365. 1877. Tipo: VENEZUELA. Rio Orinoco, A. Humboldt \& A. Bonpland s.n. (holótipo, E; isótipos, BM, NY).

Material examinado: BRASIL. AMAZONAS: Rio Uatumã, estrada para hidrelétrica de Balbina, 8 e 11.VIII.1979, W. R. Buck 2654 (INPA). BAHIA: Eunápolis, Estação Veracruz, 11.VI.1999, S. Vilas BôasBastos \& C. J. Bastos 910 (ALCB). RONDÔNIA: Vilhena, 24.V.1984, C.S. Rosário et al. 540 (MG). SÃO PAULO: Santo André, IX.1920, F. C. Hoehne s.n. (SP 5561); São Paulo, 24.IX.1923, F. C. Hoehne s.n. (SP 169940).

Apresenta distribuição Neotropical e no Brasil é conhecida para os estados do AM, PA, BA, MT e RJ, sendo aqui citada pela primeira vez para RO e SP. Ocorre sobre troncos em decomposição e pedras úmidas, 0-800 m. Status de conservação: Baixo risco (LC).

18. Hypnella pilifera (Hook. \& Wilson) A. Jaeger, Ber. Thätigk. St. Gallischen Naturwiss. Ges. 1875-76: 366. 1877. Tipo: BRASIL. RIO DE JANEIRO: Serra dos Órgãos, III.1837, C.A. Gardner 89 (lectótipo, BM, designado por Crosby et al. (1985); isolectótipos, BM, FH, NY). Material examinado: BRASIL. MINAS GERAIS: Monte Verde, 14.I.2006, D.F. Peralta et al. 3518 (SP); Lima Duarte, 7.VIII.1993, O. Yano et al. 20091 (SP). PARANÁ: Balsa Nova, 20.VI.1974, D.M. Vital 3354 (SP); Morretes, 5.VII.1991, O. Yano et al. 15463 (SP). RIO DE JANEIRO: Teresópolis, Serra dos Órgãos, VIII.1958, R. Schnell 8307 (RB); Santa Maria Madalena, P.E. Desengano, Base da Pedra do Desengano, início do afloramento rochoso,
15.V.2007, T. F. Vaz-Imbassahy et al. 158 (R). RIO GRANDE DO SUL: Montenegro, Linha de Júlio de Castilhos, 8.XI.1949, A. Sehnem 4035 (ALCB, INPA, RB). Santa Catarina: Serra Geral, V.1891, E. Ule s.n. (MG 20110). SÃO PAULO: Campos do Jordão, 17.XII.1986, C. Giancotti 72 (SP); Cunha, 22.VI.2006, D. F. Peralta et al. 3809 (SP); Paranapiacaba, 15.II.1962, A. Baranov 136(SP); Piquete, 23.X.2006, D. F. Peralta et al. 4137 (SP).

Apresenta distribuição Neotropical e no Brasil é conhecida para os estados da PB, MG, ES, RJ, SP, PR, SC e RS. Ocorre sobre solo, troncos de árvores e arbustos vivos, troncos em decomposição e pedras, freqüentemente associada a cursos de água, 0-2000 m. Status de conservação: Baixo risco (LC).

19. Hypnella punctata Broth., Nat. Pflanzenfam. 1(3): 950. 1907. Tipo: BRASIL. RIO DE JANEIRO: A.F.M. Glaziou s.n. (holótipo, BM).

Fig. $1 \mathrm{q}-\mathrm{t}$

Distribui-se no Caribe, Venezuela e Brasil, onde é conhecida somente para o estado do RJ, sem informação sobre substrato ou altitude. Status de conservação: Criticamente em perigo (CR).

Vaz \& Costa (2006a) excluíram esta espécie do seu estudo para o Rio de Janeiro, visto que nenhum material oriundo do estado pôde ser examinado, incluindo o tipo. Entretanto, Allen (1986) estudou detalhadamente o holótipo depositado no BM. Assim sendo, o táxon foi considerado como $\mathrm{CR}$ no país, visto que a única coleção conhecida (tipo) foi realizada há mais de 160 anos, e que tanto os esforços de coleta realizados no estado, quanto o estudo das coleções dos principais herbários do país, não resultaram em novos registros.

20. Lepidopilidium aureo-purpureum (Geh. \& Hampe) Broth., Nat. Pflanzenfam. 1: 944. 1907. Tipo: BRASIL. SÃO PAULO: Apiaí, VI.1879, J.J. Puiggari 179 (holótipo, HBG; isótipo, JE).

Material examinado: BRASIL. PERNAMBUCO: Caruaru, Brejo dos Cavalos, 25.VIII.1987, K. C. Pôrto 2438, 2449 (UFP). RIO DE JANEIRO: Itatiaia, trilha para Véu da Noiva, 21.VIII.2005, D. P. Costa et al. 4499 (RB); Santa Maria Madalena, P.E. Desengano, trilha para Pedra do Desengano, 15.V.2007, T. F. Vaz- 
Imbassahy et al. 138 (R); ibidem, Morumbeca do Imbé, trilha após oriacho, 16.V.2007, T. F. Vaz-Imbassahy et al. 172 (RB). SANTA CATARINA: Tubarão, VIII.1890, E. Ule 94 (R). SÃO PAULO: Guapiara, 12.IV.1993, D. M. Vital s.n. (SP 387850); Itanhaém, 13.XI.1983, O. Yano \& M. Marcelli 8597 (SP); Mogi das Cruzes, 25.VIII.2005, D. F. Peralta et al. 2795 (SP, como L. portoricense); Salesópolis, 21.III.1991, D. M. Vital s.n. (SP387191); Santo André, 8.III.2007, O. Yano \& J. Bordin 29429 (SP, como Lepidopilum brevipes); São Paulo, 14.XII.1992, O. Yano \& M. Marcelli 17777 (SP); Ubatuba, 17.II.2004, D. F. Peralta et al. 2118 (SP, como L. portoricense).

Endêmica do Brasil, conhecida para os estados do RJ, SP e SC, sendo aqui citada pela primeira vez para o PE. Ocorre sobre troncos de árvore, arbusto e cipó e troncos em decomposição, 0-1100 m. Status de conservação: Baixo risco (LC).

Apesar de apresentar ocorrência descontínua na Mata Atlântica, acredita-se que novos registros em localidades intermediárias irão ampliar sua distribuição ao longo deste bioma.

21. Lepidopilidium brevisetum (Hampe) Broth., Nat. Pflanzenfam. 1: 944. 1907. Tipo: BRASIL. Vizinhança do Rio de Janeiro: A.F.M. Glaziou s.n. (holótipo, BM).

Material examinado: BRASIL.ALAGOAS: Murici, 25.III.2006, L.D.P. Alvarenga s.n. (UFP 45848). RIO DE JANEIRO: Casimiro de Abreu, Reserva Biológica de Poço das Antas, Morro do Calcáreo, 8.III.1994, D.P. Costa et al. 2002 (RB); Itatiaia, Mont Serrat, 18.VII.1902, P. Dusén s.n. (R 82047, 14052); Rio de Janeiro, Corcovado, XI.1893, E. Ule 1705 (R). SÃO PAULO: São Paulo, 14.XII.1992, O. Yano \&M. Marcelli 17830 (SP).

Endêmica do Brasil, conhecida para os estados do ES, RJ, SP, SC e RS, sendo aqui citada pela primeira vez para AL. Ocorre sobre troncos de árvores e arbustos, freqüentemente associada a cursos de água, 0-1200 m. Status de conservação: Baixo risco (LC).

22. Lepidopilidium laevisetum (Hampe) Broth., Nat. Pflanzenfam. 1: 944. 1907. Tipo: BRASIL. RIO DE JANEIRO: A.F.M. Glaziou 9235 (isótipo, BM).
Material examinado: BRASIL. MINAS GERAIS: Santa Bárbara, 27.V.1983, O. Yano \& J. R. Pirani 7353 (SP). RIO DE JANEIRO: Itatiaia, 9.VII.1991, D. $M$. Vital s.n. (SP 387633); Nova Friburgo, 2.V.1988, D. P. Costa et al. 586(RB); Magé, Pico do Frade, 7.II.1985, C. Farney et al. 646 (RB); Resende, 21.VI.1983, O. Yano 7554 (SP); Santa Maria Madalena, P.E. Desengano, 29.VI.1989, A. Costa et al. 294 (RB). SÃO PAULO: São Paulo, Pindamonhangaba, 14.XII.1971, D.M. Vital 1940 (SP).

Conhecida para a Venezuela e Brasil, onde ocorre nos estados do RJ, SP, PR e RS, sendo aqui citada pela primeira vez para MG. Ocorre sobre troncos de árvores e solo, 0-1780 m. Status de conservação: Baixo Risco (LC).

23. Lepidopilidium plebejum (Müll. Hal.) Sehnem, Pesquisas Bot. 33: 32. 1979. Tipo: BRASIL. SANTA CATARINA: Tubarão, X.1889, E. Ule 768; Blumenau, IX.1888, E. Ule 473 (síntipos, HBG).

Material examinado: BRASIL. RIO DE JANEIRO: Nova Friburgo, 11.X.1990, D. P. Costa et al. 1115 (RB). Conhecida para a América do Sul e no Brasil para os estados de RJ, SC e RS, ocorrendo sobre tronco e ramos de árvores, próximos a cursos de água, 0-1400 m. Status de conservação: Dados deficientes (DD).

24. Lepidopilidium portoricense (Müll. Hal.) H.A. Crum \& Steere, Bryologist 59: 253. 1956. Tipo: PORTO RICO. Monte Cuyón, Sintenis s.n. (holótipo, NY?).

Material examinado: BRASIL. PERNAMBUCO: Inajá, 6.IX.1980, O. Yano \& D. Andrade-Lima 2939, 2954 (SP); Jaqueira, RPPN Frei Caneca, 4.X.2005, A. S. M. Silva s.n. (UFP 44832). RIO DE JANEIRO: Petrópolis, Serra da Estrela, riacho que leva ao Morro do Castelo, 11.VIII.2006, T.F. Vaz-Imbassahy 83 et. al. (RB).

Apresenta distribuição Neotropical e no Brasil é conhecida para os estados do CE e SC, sendo aqui citada pela primeira vez para $\mathrm{PE} \mathrm{e}$ RJ. Ocorre sobre troncos e ramos de árvores e arbustos, próximos a cursos de água, 0-700 m. Status de conservação: Baixo risco (LC).

Apesar da ocorrência descontínua na Mata Atlântica do país, novos registros nas Regiões Nordeste, Sudeste e Sul devem ampliar sua distribuição ao longo deste bioma. 
25. Lepidopilum affine Müll. Hal., Linnaea 21: 192. 1848. Tipo: SURINAME. PARAMARIBO: VI.1844, H.A.H. Kegel 741 (isótipos, H-BR, JE).

Material examinado: BRASIL. SÃO PAULO: São Paulo, Parque Estadual das Fontes do Ipiranga, 29.VII.1987, D. M. Vital 15069 (SP).

Apresenta distribuição Neotropical e no Brasil é conhecida para os estados do AP, AC, AM, SP. Ocorre sobre tronco e ramos de árvores e lianas, 0-2000 m. Status de conservação: Baixo risco (LC).

Apesar da espécie apresentar distribuição disjunta no país e de terem sido consultadas as coleções dos principais herbários, somente um material de São Paulo pôde ser examinado. Os registros de L. affine em Yano (1981, citados como L. subobtusulum Broth.) para os estados do MG, PR, RS, SC e SP pertencem a $L$. subsubulatum Geh. \& Hampe, e por isso foram aqui excluídos da distribuição no Brasil. Esta espécie provavelmente encontra-se restrita a região Amazônica (Churchill 1988), e o registro para o Parque Estadual das Fontes do Ipiranga, em São Paulo, possivelmente representa uma introdução do táxon, já que este Parque é o arboreto de um Jardim Botânico.

26. Lepidopilum brevipes Mitt., J. Linn. Soc., Bot. 12: 376. 1869. Tipo: PERU. Andes Peruvianae, Tabalosos, R. Spruce s.n. (holótipo, NY).

Material examinado: BRASIL. MINAS GERAIS: Lima Duarte, 22.I.1987, G. Sousa s.n. (SP 389531). SÃO PAULO: Ibiúna, 19.III.1999, O. Yano \& I. Cordeiro 25645 (SP).

Apresenta distribuição Neotropical e no Brasil é conhecida para os estados de RO, AM, ES, SP, PR, SC e RS, sendo aqui citada pela primeira vez para MG. Ocorre sobre troncos e ramos de árvores, 850-1300 m. Status de conservação: Baixo risco (LC).

De acordo com Churchill (1988) L. brevipes varia em relação à forma do filídio (ovado-lanceolado a oblongo-lanceolado) e às células da lâmina (estreito a largamente fusiformes), o que não pode ser confirmado devido a escassez de material examinado.
27. Lepidopilum caudicaule Müll. Hal., Hedwigia 39: 272. 1900. Tipo: BRASIL. RIO DE JANEIRO: Serra dos Órgãos, XII.1891, E. Ule 1249 (holótipo, HBG; isótipo, R!).

Material examinado: BRASIL. PERNAMBUCO: Caruaru, Brejo dos Cavalos, 27.VIII.1987, K.P. Pôrto 2599 (UFP). RIO DE JANEIRO: Petrópolis, Serra dos Órgãos, XII.1891, E. Ule 1249 (isótipo, R); ibidem, Serra da Estrela, trilha para Morro do Castelo, 11.VIII.2006, T. F. Vaz-Imbassahy et al. 98 (RB); Rio de Janeiro, PARNA Tijuca, Corcovado, 15.II.2007, T.F. Vaz-Imbassahyetal. 112 (R). SANTA CATARINA: Bom Retiro, Campo dos Padres, 15.I.1957, A. Sehnem 6993 (PACA).

Endêmica do Brasil, conhecida para os estados do RJ e SC, sendo aqui citada pela primeira vez para PE. Ocorre sobre pedras e tronco de árvore, 150-1700 m. Status de conservação: Baixo risco (LC).

Apesar da ocorrência descontínua na Mata Atlântica acredita-se que sua distribuição seja mais ampla neste bioma.

28. Lepidopilum cubense (Sull.) Mitt., J. Linn. Soc., Bot. 12: 384. 1869. Tipo: CUBA. C. Wright 85 p.p. (isótipos, BM, FH, G, L, NY). Material examinado: BRASIL. CEARÁ: Ubajara, H.C. Oliveira 207(SP).

Apresenta distribuição Neotropical e no Brasil é conhecida para os estados do $\mathrm{CE}$ e BA, ocorrendo sobre tronco em decomposição, cerca de 800 m. Status de conservação: dados deficientes (DD).

29. Lepidopilum erectiusculum (Taylor) Mitt., J. Linn. Soc., Bot. 12: 372. 1872. Tipo: EQUADOR. Floresta Esmeralda, 1827, W. Jamenson s.n. (holótipo, FH; isótipos, BM, E, FH). Fig. $1 \mathrm{u}-\mathrm{y}$ Material examinado: BRASIL. ACRE: Cruzeiro do Sul, 27.IV.1971, G. Prance et al. 12551 (INPA).

Apresenta distribuição Neotropical, sendo aqui citada pela primeira vez para o Brasil, ocorrendo ao nível do mar, sobre troncos de árvore em Floresta Ombrófila Aberta. Status de conservação: Dados deficientes (DD).

Segundo Churchill (1988) esta é uma espécie representada por poucas coleções (ocorrendo do Equador até o Norte do Chile), 
e conseqüentemente não muito bem caracterizada. É semelhante a L. longifolium, quanto à forma do filídio (lanceolado a oblongolanceolado), diferenciando-se pela margem fortemente serreada, com dentes marginais projetados, que em L. longifolium é serrulada a levemente serreada, e sem dentes.

30. Lepidopilum longifolium Hampe, Ann. Sci. Nat. Bot. V, 4: 365. 1865. Tipo: COLÔMBIA. CUNDINAMARCA: Tequendama: Escaleros, Lindg s.n. (lectótipo, BM, designado por Churchill 1988).

Material examinado: BRASIL. RIO DE JANEIRO: Itatiaia, trilha para Véu da Noiva, 15.II.1994, A. J. Andrade s.n. (RB 382306); ibidem, Maromba, 17.IX.1955, O. Fidalgo \& E. P. Kauffmann Fidalgo Eg-19(RB). SÃO PAULO: Bananal, 26.IX.1978, O. Yano 1241 (SP).

Apresenta distribuição Neotropical e no Brasil é conhecida para o estado de RJ, sendo aqui citada pela primeira vez para SP. Ocorre sobre tronco de árvore, próxima a cursos de água, 450-1100 m. Status de conservação: Vulnerável (VU).

Restrita a Mata Atlântica do sudeste do país e conhecida apenas por três coleções, duas realizadas há mais de 20 anos. As duas coleções do PARNA-Itatiaia, foram realizadas em localidades que sofrem forte pressão turística, as Cahoeiras do Maromba e do Véu da Noiva.

31. Lepidopilum muelleri (Hampe) Spruce, Ann. Sci. Nat. Bot., 4: 365. 1865. Tipo: VENEZUELA. R. Moritz s.n. (isótipos, BM, S).

Material examinado: BRASIL. PERNAMBUCO: Caruaru, Brejo dos Cavalos, 27.VIII.1987, K. C. Pôrto 2589, 2590, 2595 (UFP); ibidem, 29.VIII.1980, O. Yano \& D. Andrade-Lima 2743 (SP); Taquaritinga do Norte, 24.VIII.1980, O. Yano \& D. Andrade-Lima 2630 (SP). MINAS GERAIS: Camanducaia, 14.I.2006, D. F. Peralta et al. 3412 (SP); Monte Verde, 14.I.2006, D. F. Peralta et al. 35524 (SP). RIO DE JANEIRO: Angra dos Reis, 21.III.1995, O. Yano et al. 23671 (SP, como Hookeriopsis angustiretis); Itatiaia, Mont Serrat, 11.V.1902, P. Dusén 199 (R); Nova Friburgo, Morro do Curuzu, 15.VII.1987, D. P. Costa et al. 303 (RB); Petrópolis, Serra da Estrela, trilha para Morro do Castelo, 11.VIII.2006, T. F. Vaz-Imbassahy 84(RB); Rio de Janeiro, PARNA Tijuca, 19.VII.2006, T. F. VazImbassahy et al. 2 (R); Santa Maria Madalena, trilha para Pico do Desengano, 15.V.2007, T. F. VazImbassahy et al. 131 (R). SÃO PAULO: Cananéia, 5.IV.1978, O. Yano 1016(SP); Cunha, 22.VI.2006, D. F. Peralta etal. 3821 (SP); Guarujá,4.V.2004, D. F. Peralta et al. 2429 (SP); Guapiara, 16.I.1997, D. M. Vital s.n. (SP 388337); Juquitiba, 14.VII.1977, Vital 7143 (SP); Mogi das Cruzes, 24.X.2005, D. F. Peralta \& M. S. Mialich 2921 (SP, como Lepidopilidium portoricense); Peruíbe, 22.IV.1989, O. Yano \& Z.R.. Mello 12654 (SP); Pindamonhangaba, 18.X.1994, S. Visnadi \& D. M. Vital 2386 (SP); Piquete, 23.X.2006, D.F. Peralta et al. 4135 (SP); Salesópolis, 20.III.2001, D. M. Vital s.n. (SP387077); Santo André, 3.X.2004,D. F. Peralta 2484 (SP); São José do Barreiro, 8.XI.1978, O. Yano 1306 (SP); São Paulo, 29.VIII.1920, F. C. Hoehne s.n.. (SP, como Lepidopilidium gracilifrons); ibidem, 25.VI.1991, O. Yano et al. 15389 (SP).

Apresenta distribuição Neotropical e no Brasil é conhecida para os estados do AM, PE, MG, RJ, SP e RS. Ocorre sobre troncos e ramos de árvore, troncos em decomposição e pedras, 0-2100 m. Status de conservação: Baixo risco (LC).

É muito similar a $L$. subsubulatum no que diz respeito à forma do filídio, aos filídios periqueciais e esporófito. As espécies se diferenciam somente pela forma do ápice do filídio, acuminado e com células romboidais a sinuadas em L. muelleri e longo-acuminado e com células lineares em $L$. subsubulatum.

32. Lepidopilum ovalifolium (Duby) Broth., Bih. Kongl. Svenska Vetensk.-Akad. Handl., 3: 34. 1895. Tipo: BOLÍVIA. COCHABAMBA: Incacorral, I.1908, Th. Herzog s.n. (holótipo, B). Material examinado: BRASIL. RIO DE JANEIRO: Campos dos Goytacazes, P.E. Desengano, 1.V.2007, T. F. Vaz-Imbassahy et al. 183 (R); Itatiaia, trilha para Véu da Noiva, 15.II.1994, A. J. Andrade s.n. (RB 382347); Nova Friburgo, estrada para Salinas, 10.XII.1987, D. P. Costa et al. 455 (RB); Petrópolis, Serra da Estrela, Comunidade Lopes Freire, 11.VIII.2006, T. F. Vaz-Imbassahy et al. 102 (R); Rio de Janeiro, PARNA Tijuca, 19.VIII.2006, T. F. VazImbassahy et al. 7 (R); Santa Maria Madalena, P.E. Desengano, trilha para o Pico do Desengano, 15.V.2007, T. F. Vaz-Imbassahy et al. 132 (RB). RIO 
GRANDE DO SUL: Caxias do Sul, Vila Oliva, 12.I.1947, A. Sehnem 2644 (ALCB). SÃO PAULO: São Paulo, 16.I.1987, D. M. Vital 14570 (SP); Ubatuba, 18.VIII.1987, D. M. Vital 15220 (SP).

Endêmica do Brasil, conhecida somente para formações de Mata Atlântica dos estados do RJ, SP, SC e RS, ocorrendo sobre solo e pedras, freqüentemente associada a cursos de água, 0-1200 m. Status de conservação: Baixo risco (LC).

33. Lepidopilum pallidonitens (Müll. Hal.) Paris, Ind. Bryol. Suppl. 223. 1900. Tipo: BOLÍVIA. COCHABAMBA: Próximo a Choquecamata, VI.1889, J.N.E. Germain s.n. (isótipo, NY).

Fig. 2 a-e Material examinado: BRASIL. ACRE: Juruá, IX.1901, E. Ule s.n. (indicado como tipo de Lepidopilum spathulatum, MG 20096). AMAZONAS: Serra do Curicuriari, 4.XI.1971, G. Prance et al. 16068 (INPA).

Apresenta distribuição Neotropical (Costa Rica até o norte da Bolívia), sendo aqui citada pela primeira vez para o Brasil, estados do AC e AM. Ocorre sobre troncos de árvore e pedras, 0-450 m. Status de conservação: Dados deficientes (DD).

Caracteriza-se pela margem serreada, sem células diferenciadas na borda, e seta espinhosa.

34. Lepidopilum polytrichoides (Hedw.) Brid., Bryol. Univ. 2: 269. 1827. Tipo: JAMAICA. O. Swartz s.n. (isótipos, BM, H-BR, NY). Material examinado: BRASIL. AMAZONAS: São Gabriel da Cachoeira, 10.VII.1979, O. Yano 1859 (SP).

Apresenta distribuição Neotropical e no Brasil está restrita à região Amazônica, estados de RO, AC, AM, PA e MT, ocorrendo sobre troncos de árvore, 0-200 m. Status de conservação: Baixo risco (LC).

35. Lepidopilum scabrisetum (Schwägr.) Steere, Bryologist 51: 140 (1948). Tipo: GUIANA. D. Richard s.n. (holótipo, G; isótipos, BM, NY). Material examinado: BRASIL. ALAGOAS: Murici, 2.XII.2004, K. C. Pôrto s.n. (UFP45830). AMAZONAS: BR 174, entre Manaus e São Gabriel, 9-12.VII.1979, W. R. Buck 2478(INPA). BAHIA: Ilhéus, 14.III.1995,
S. L.Oliveira 80 (ALCB, como Lepidopilidium gracilifrons). MINAS GERAIS: Monte Verde, 14.I.2006, D. F. Peralta et al. 3450 (SP). PARÁ: Serra do Cachimbo, 10-15.V.1983, W. D.Reese 16711 (INPA). PARANÁ: Guaíra, 17.III.1982, O. Yano 4022 (SP). PERNAMBUCO: Altinho, 29.VIII.1980, O. Yano \& D. Andrade-Lima 2784 (SP); RIO DE JANEIRO: Parati, km 204 da Rodovia Rio-Santos 8.V.1991, D. P. Costa et al. 1479 (RB); Petrópolis, Serra da Estrela, trilha para Morro do Castelo, 11.V.206, T. F. Vaz-Imbassahy et al. 95 (RB); Resende, 30.XI.1985, O. Yano \& S. Visnadi 9828(SP); Rio de Janeiro, PARNATijuca, 19.VII.2006, T. F. Vaz-Imbassahy et al. 9 (RB); Santa Maria Madalena, P.E. Desengano, 15.V.2007, T.F. VazImbassahy etal. 133 (R). RONDÔNIA: Alto Condeias, 16.V.1982, A. Fife et al. 4169 (INPA). SANTA CATARINA: Nova Venécia, VII.1891, E. Ule s.n. (MG 20099); Serra Geral, 27.IX.1984, D. M. Vital \& W. R. Buck 12352 (SP); SÃO PAULO: Embú Guaçú, 14.XI.1983, O. Yano 8682 (SP); Guarujá, 4.V.2004, D. F. Peralta et al. 2427 (SP); Ibiúna, 29.V.1983, O. Yano 7422 (SP); Pindamonhangaba, 18.X.1994, S. Visnadi \& D. M. Vital 2412 (SP); São Paulo, IX.1921, F. C. Hoehne s.n. (SP 5906, como Lepidopilidium gracilifrons); Ubatuba, 22.XI.2003, D. F. Peralta et al. 1616 (SP, como Lepidopilum stolonaceum).

Apresenta distribuição Neotropical e no Brasil encontra-se amplamente distribuída (RR, AP, AC, AM, PA, PE, BA, MT, MG, SP, RJ, $\mathrm{SC}$ e RS), sendo aqui citada pela primeira vez para RO, AL e PR. Ocorre sobre pedras, troncos e ramos de árvore, troncos em decomposição, e mais raramente sobre solo, 0-1700 m. Status de conservação: Baixo risco (LC).

Esta espécie é polimórfica, sendo caracterizada pelos filídios 2-3 vezes mais largos do que longos, com ápice acuminado. A variação morfológica também pode ser encontrada na ornamentação da seta, como indicada por Vaz \& Costa (2006b) e observada nas diferentes coleções examinadas.

36. Lepidopilum subsubulatum Geh. \& Hampe, Vidensk. Meddel. Dansk. Naturhist. Foren. Kjøbenhavn, ser. 4, 1: 123. 1879. Tipo: BRAZIL. SÃO PAULO: Apiaí, 1879, J.J. Puiggari 53 (lectótipo, G!, designado por Churchill (1988); isolectótipo, H-BR).

Material examinado: BRASIL. MINAS GERAIS: Santa Bárbara, 22.X.1994, S. Visnadi \& D. M. Vital 

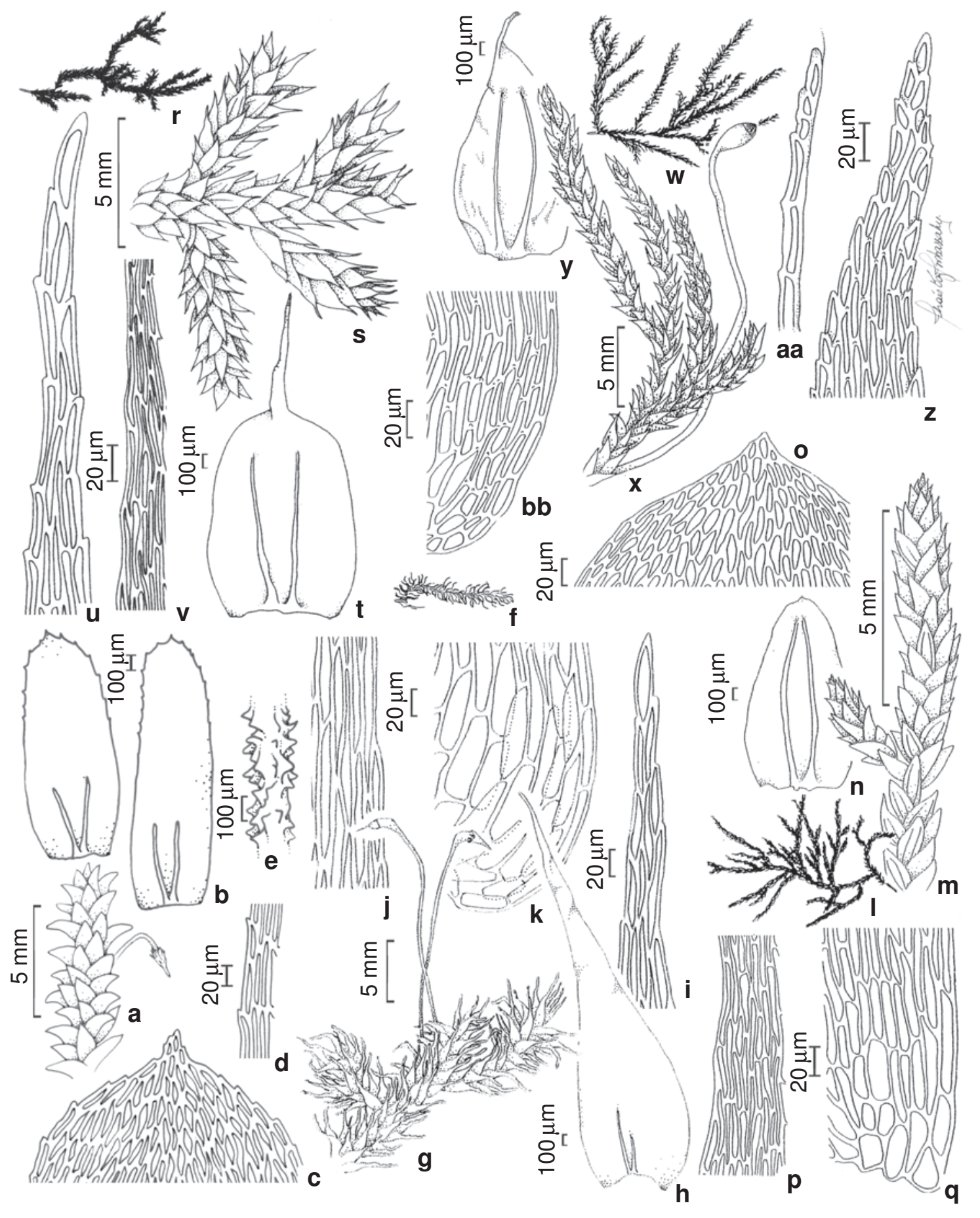

Figura 2-a-e. Lepidopilum pallidonitens (Müll. Hal.) Paris - a. detalhe do gametófito com esporófito; b. filídios; c. células do ápice do filídio; d. células da margem do filídio; e. detalhe da seta espinhosa (Prance 16068). f-k. Philophyllum tenuifolium (Mitt.) Broth. -f. hábito; g. detalhe do gametófito com esporófito; h. filídio; i. células do ápice do filídio; j. células da margem do filídio; k. células da base do filídio (Schäfer-Verwimp \& Verwimp 14530); 1-q. Thamniopsis pendula (Hook.) M. Fleisch. - 1. hábito; m. detalhe do gametófito; $n$. filídio; o. células do ápice do filídio; p. células da margem do filídio; q. células da base do filídio (Raddi s.n. PI). r-v. T. purpureophylla (Müll. Hal.) W. R. Buck-r. hábito; s. detalhe do gametófito; t. filídio; u. células do ápice do filídio; v. células da margem do filídio (Luetzelburg 6269). w-bb. Trachyxiphium variabile (Mitt.) W. R. Buck - w. hábito; x. detalhe do gametófito com esporófito; y. filídio; z. células do ápice do filídio; aa. detalhe do ápice da costa; bb. células da base do filídio (Costa 739). 
2509 (SP). PARANÁ: Curitiba, 29.IV.1988, O. Yano \& T. Shirata 11406(SP). PERNAMBUCO: Caruaru, Brejo dos Cavalos, 25.VIII.1987, K. C. Pôrto 2453b (UFP). RIO DE JANEIRO: Itatiaia, Mauá, 8.II.1925, M. C. V. Bandeira s.n. (RB 174405); Nova Friburgo, Duas Pedras, 23.I.1955, A. Sehnem 6756 (PACA); ibidem, Macaé de Cima, 3.V.1988, D. P. Costa et al. 599 (RB); Petrópolis, Serra da Estrela, 'Morro das Antenas', 10.VIII.2006, T.F. Vaz-Imbassahy et al. 75 (R); Rio de Janeiro, Corcovado, 21.XI.1891, E. Ule 1250 (R); Santa Maria Madalena, P.E. Desengano, 15.V.2007, T. F. Vaz-Imbassahyet al. 136(R). SANTA CATARINA: Campo dos Padres, Bom Retiro, 18.I.1957, A. Sehnem 7090, 7090a (PACA); Ilha de Santa Catarina, Morro do Antão, 3.I.1948, A. Sehnem 3203 (PACA). SÃO PAULO: Guapiara, 24.VII.1991, D. M. Vital s.n. (SP387717); Ibiúna, 15.I.1988, O. Yano \& M. Marcelli 11154, 11163 (SP); Mogi das Cruzes, 25.VIII.2005, D.F. Peralta et al. 2798 (SP, como Lepidopilidium portoricense); Pindamonhangaba, 29.IV.1994, W. R. Buck 26450 (SP); Piquete, 23.X.2006, D. F. Peralta et al. 4139 (SP); Rio Grande da Serra, 26.XII.1960, A. Baranov 81 (SP); São Paulo, O. Yano et al. 16808 (SP).

Endêmica do Brasil, conhecida para os estados de MG, RJ, SP, PR, SC e RS, sendo aqui citada pela primeira vez para $\mathrm{PE}$, ampliando assim sua distribuição para o nordeste do país. Ocorre sobre folhas, pedras, troncos e ramos de árvores, 0-2000 m. Os registros de $L$. subobtusulum citados por Yano (1981) para os estados de MG, PR, RS, SC e SP pertencem a L. subsubulatum. Status de conservação: Baixo risco (LC).

37. Lepidopilum surinamense Müll. Hal., Linnaea 21: 193. 1848. Tipo: SURINAME. MARIEPASTON: H.A.H. Kegel 1406 (isótipos, H-BR, JE).

Material examinado: BRASIL. ACRE. Tarauacá, Vale do Alto Juruá, 20.XI.1995, D. P. Costa et al. $2693 a$ (RB, como Lepidopilum polytrichoides); AMAZONAS: Rio Madeira, III.1902, E. Ule s.n. (MG 20097); Rio Uatumã, 20.IX.1978, R. C. L. Lisboa et al. 1049 (INPA); São Gabriel da Cachoeira, 17.VII.1979, O. Yano 2026(SP). BAHIA: Ihéus, 17.VII.1991,D. M. Vital s.n. (SP373114). MATOGROSSO: Aripuanã, 25.IX.1975, R. C. L. Lisboa et al. 251 (MG). PARÁ: Augusto Corrêa, 5.XII.1993, R. C. Lobato \& P. Cavalcante 1585 (MG); Bragança, 1.XII.1993, J. Sales \& C. S. Rosário 2060(MG); Capitão Poço, 13.XII.1993, J. Sales \& C. S.Rosário 2184(MG);
Parauapebas, 23.X.1992, R. C. L. Lisboa et al. 1953 (MG); Peixe-Boi, 18.IX.1989, R. C. L. Lisboa \& N. Rosa 6397(MG); SerradoCachimbo, 10-15.V.1983, W.D. Reese 16667 (INPA); Tucuruí, 21.XII.1983, R. C. P. Santos 750 (MG); Vizeu, 1.XII.1993, R. C. Lobato \& P. Cavalcante 1341 (MG). RIO DE JANEIRO: Angra dos Reis, Ilha Grande, trilha para Praia de Palmas, 21.II.1995, M. I. M. N. Oliveira-e-Silva 2855 (HRJ); ibidem, trilha para Caxadaço, 18.IV.1995, M. I. M.N. Oliveira-e-Silva 4080 (HRJ). RONDÔNIA: Ariquemes, 15.V.1982, A. Fife et al. 4143 (INPA); Guarajá-Mirim, 28.I.1983, $R$. C. L. Lisboa et al. 521 (MG). SÃO PAULO: Santos, 19.VI.1988, A.Schäfer-Verwimp \& I. Verwimp 9696 (SP, como Lepidopilum polytrichoides).

Apresenta distribuição Neotropical e no Brasil apresenta uma distribuição disjunta entre as Florestas Amazônica e Atlântica (RO, AP, AM, PA, AL, BA, RJ e SP), sendo aqui citada pela primeira vez para o AC e Região CentroOeste (MT). Ocorre sobre troncos e ramos de árvores e arbustos, ocasionalmente sobre solo arenoso e raramente sobre troncos em decomposição e folhas, 0-300 m. Status de conservação: Baixo risco (LC).

As características diagnósticas de $L$. surinamense incluem o filídio bordeado por 12 fileiras de células lineares e mais estreitas que contrastam com as células laxas e romboidais da lâmina, bem como o filídio periquecial que apresenta costa dupla.

38. Lepidopilum tortifolium Mitt., J. Linn. Soc., Bot. 12: 374. 1869. Tipo: EQUADOR. BOMBONASA: R. Spruce 783 (lectótipo, NY, designado por Churchill 1988).

Material examinado: BRASIL.AMAZONAS: Entre Manaus e São Gabriel da Cachoeira, 9-12.VII.1979, W.R. Buck 2506 (INPA); São Gabriel da Cachoeira, 10.VII.1979, O. Yano 1847 (SP).

Apresenta distribuição Neotropical e no Brasil é conhecida para a região Amazônica, estados do AC e AM, onde ocorre sobre pedras úmidas, 130-450 m. Status de conservação: Baixo risco (LC).

Reconhecida pelos filídios oblongos a oblongo-obovados, com ápice variando de obtuso ou rotundo a apiculado ou abruptamente curtoacuminado, costa alcançando cerca de 1/2-2/3 do comprimento do filídio. Pode ser confundida 
com $L$. surinamense, mas se diferencia por apresentar borda mais espessa e costa mais longa.

39. Philophyllum tenuifolium (Mitt.) Broth., Nat. Pflanzenfam. 1: 945. 1907. Tipo: BRASIL. W.J. Burchell 2231 (holótipo, NY; isótipos, HBR, NY).

Fig. 2 f-k

Material examinado: BRASIL. RIO DE JANEIRO: 'Serra de Macaé', II.1900, E. Ule s.n. (MG 20145). SÃO PAULO: Santo André, 14.X.1921, F. C. Hoehne 480 (SP); Serra da Bocaina, 'Pedra das Bromélias' 1.VI.1991, A. Schäfer-Verwimp \& I. Verwimp 14530 (NY).

Apresenta distribuição Neotropical (Peru e Guatemala) e no Brasil é conhecida para as Regiões Sudeste e Sul, estados de MG, RJ, SP e SC, ocorrendo em tanques e folhas de bromélias, 0-2200 m. Status de conservação: Baixo risco (LC).

Philophyllum tenuifolium é uma espécie com microhabitat restrito aos tanques de bromélias, podendo estar submersa ou emersa. Este gênero foi anteriormente posicionado em Leucomiaceae e posteriormente posicionado em Pilotrichaceae (Buck 1992; Goffinet \& Buck 2004).

40. Pilotrichum bipinnatum (Schwäegr.) Brid., Muscol. Recent. Suppl. 4: 140. 1819. Tipo: GUIANA FRANCESA. D. Richard s.n. (holótipo, PC).

Material examinado: BRASIL. AMAPÁ: Oiapoque, 9.XII.1984, S. Mori s.n. (MG 109661). AMAZONAS: Careiro, A. Filho s.n. (UFP 4744). Manaus, D. Griffin III et al. 163 (MG). BAHIA: Eunápolis, 9.VI.1999, S. Vilas Bôas-Bastos \& C.J. Bastos 351 (ALCB). PARÁ: Marajó, Cavalcante 2044 (MG); Melgaço, 21.X.2004, L.D.P. Alvarenga 243 (MG, como Pilotrichum evanescens). RORAIMA: BR 174 (Manaus-Venezuela), 16-17.XI.1977, W.R. Buck et al. 1828 (INPA); Uraricoeana, 2.XII.1973, G. Prance et al. 19962 (INPA, como P. evanescens).

Apresenta distribuição Neotropical e no Brasil é conhecida para os estados de RO, AP, AC, AM, PA, BA e MG, sendo aqui citada pela primeira vez para RR. Ocorre sobre troncos e ramos de árvores, ao nível do mar. Status de conservação: Baixo risco (LC).

Embora alguns autores como Crosby (1969), Florschütz de-Waard (1986), Buck (1998), entre outros, afirmem que P. bipinnatum não apresenta propágulos, Vilas Bôas-Bastos \& Bastos (2002) registraram a ocorrência destes em exemplares da Bahia.

Caracterizada pelos filídios obovados com ápice abruptamente agudo a curto-acuminado, contrastando com os filídios oblongo-ovados com ápice gradualmente agudo de $P$. evanescens.

41. Pilotrichum evanescens (Müll. Hal.) Crosby, Bryologist 72: 326. 1969. Tipo: SURINAME. PARAMARIBO: H.A.H. Kegel 742 (lectótipo, GOET, designado por Crosby 1969).

Material examinado: BRASIL. AMAZONAS: Igarapé Santa Luzia, 16-17.VIII.1979, W. R. Buck 2874 (MG); Manaus, Reserva Ducke (INPA), 16.VII.1996, D. P. Costa et al. 3139 (RB). MATO GROSSO: Aripuanã, 28.IX.1975, R. C. L. Lisboa et al. 381 (INPA). PARÁ: Bacarena, 16.XI.2001, R. C. L. Lisboa 7104 (MG); Bragança, 11.XII.1993, J. Sales \& C. S. Rosário 2047 (MG); Vizeu, 1.XII.1993, R. C. Lobato \& P. Cavalcante 1354 (MG); Parauapebas, 19.X.1992, R. C. L. Lisboa et al. 1756 (MG). PERNAMBUCO: Rio Formoso, 18.VII.1985, K. C. Pôrto s.n. (UFP 25023). RIO DE JANEIRO: Santa Maria Madalena, P.E. Desengano, 15.VI.2000, N. D. Santos 556 (RFFP). SÃOPAULO: Cananéia, 9.X.1980, O. Yano 3083 (SP). Juquiá, 18.XI.1976, D. M. Vital 6722 (SP).

É Neotropical e no Brasil está amplamente distribuída (RR, AM, PA, PE, BA, MG, RJ, SP, PR e SC), sendo aqui citada pela primeira vez para MT. Ocorre sobre troncos em decomposição e lianas, 0-1200 m. Status de conservação: Baixo risco (LC).

42. Thamniopsis cruegeriana (Müll. Hal.) W.R. Buck, Brittonia 39: 218. 1987. Tipo: TRINIDAD. Monte Tamanaco, 10.VIII.1847, H. Crüger s.n. (lectótipo, NY, designado por Buck 1987).

Material examinado: BRASIL. MATO GROSSODO SUL: Aquidauana, 8.VI.1997, s.col. (SP284134).

Apresenta distribuição Neotropical e no Brasil apresenta ocorrência fragmentada sendo conhecida para o estado do AM e aqui citada pela primeira vez para MS. Ocorre sobre troncos em decomposição e pedras úmidas, ao nível do mar. Status de conservação: Dados deficientes (DD). 
Pode ser reconhecida pela diferenciação dos filídios do caulídio e os do ramo, sendo que os do caulídio apresentam ápice rotundo e os do ramo ápice agudo a acuminado, com células marginais formando dentes inflados e bífidos.

43. Thamniopsis incurva (Hornsch.) W. R. Buck., Brittonia 39: 218. 1987. Tipo: CHILE. A. Chamisso 1487 (lectótipo, BM, designado por Buck 1987).

Material examinado: BRASIL. BAHIA: Cachoeira, 29.IX.1991, C. J. Bastos \& A. Cerqueira 361 (ALCB). MINAS GERAIS: Fazenda Paraíso, 26.XI.1930, $Y$. Mexia 5364 (TENN). PARANÁ: Curitiba, 29.IV.1988, O. Yano \& T. Shirata 11373 (SP); Morretes, 5.VII.1991, O. Yano et al. 15437 (SP). PERNAMBUCO: Jaqueira, RPPN Frei Caneca, 14.IV.2005, M. Silva \& F. Silva s.n. (UFP 44828). RIO DE JANEIRO: Mangaratiba, km 54 da Rodovia Rio-Santos, Reserva Ecológica Rio das Pedras, 14.IX.1993, M. I. M. N. Oliveira-eSilva 657 (HRJ); Rio de Janeiro, 23.III.2004, J. M. Braga 7413 (RB); Teresópolis, 21.X.1989, O. Yano \& D. P. Costa 13564 (SP); Santa Maria Madalena, trilha para Morumbeca do Imbé, T. F. Vaz-Imbassahy et al. 168 (R); ibidem, estrada para Sossego do Imbé, Serrinha, 17.V.2007, T. F. Vaz-Imbassahy et al. 177 (RB). RIO GRANDE DO SUL: Santa Cruz do Sul, 5.X.1992, O. Yano \& E. L. Michel 17250 (SP); São Leopoldo, Fazenda São Borja, 8.V.1935, A. Sehnem 16 (PACA). SANTA CATARINA: Tubarão, VIII.1890, E. Ule s.n. (MG 20108). SÃO PAULO: Alto da Serra, 3.VIII.1921, C. Gehrt 356 (JE); Apiaí, V.1889, J. J. Puiggari 380 (JE); Bertioga, 18.X.1993, O. Yano \& M. Marcelli 20569 (SP); Caraguatatuba, 28.VII.1983, O. Yano et al. 7985 (SP); Cubatão, 18.VI.1986, D. M. Vital 13790 (SP); Cunha, 22.VI.2006, D. F. Peralta et al. 3909 (SP); Eldorado, 29.IX.1984, D. M. Vital 12499 (SP); Guarujá, 13.III.2005, D. F. Peralta \& J. Boldrin 2698 (SP); Mongaguá, 22.IV.1993, O. Yano \& M. Marcelli 18882 (SP); Peruíbe, 9.X.1988, O. Yano \& Z. R. Mello 11732 (SP); Salesópolis, 20.III.1991, D. M. Vital s.n. (SP 387091); Santo André, 3.X.2004, D. F. Peralta 2486 (SP); Santos, I.1921, J. Melzer 177(SP); São Paulo, 9.VII.1963, G. Eiten 5361 (SP); Ubatuba, 22.XI.2003, D. F. Peralta 1626 (SP).

É Neotropical e no Brasil está amplamente distribuída (AM, PA, PB, BA, MG, ES, RJ, SP, PR, SC e RS), sendo aqui citada pela primeira vez para PE. Ocorre sobre solo, troncos de árvore, troncos em decomposição e pedras, associada freqüentemente a cursos de água, 0-1400 m. Status de conservação: Baixo risco (LC).

44. Thamniopsis langsdorffii (Hook.) W.R. Buck, Brittonia 39: 218. 1987. Tipo: BRASIL. RIO DE JANEIRO: G.H. Langsdorff s. $n$. (holótipo, BM!).

Material examinado: BRASIL. MINAS GERAIS: Catas Altas, I.1921, F. C. Hoehne 396 (SP). RIO DE JANEIRO: Angra dos Reis, Ilha Grande, caminho para o Pico do Papagaio, 21.III.1995, O. Yano et al. 23689 (SP); Campos dos Goytacazes, P.E. Desengano, $T$. F. Vaz-Imbassahy et al. 184 (RB); Nova Friburgo, Macaé de Cima, Rio das Flores, 17.VIII.1987, D. P. Costa et al. 348 (RB); Petrópolis, Serra da Estrela, 10.VIII.2006, T. F. Vaz-Imbassahy et al. 54 (RB); Resende, 21.VI.1983, O. Yano 7541 (SP); Rio de Janeiro, E. Ule s.n. (R 82013); ibidem, PARNA Tijuca, 12-VII-2006, T. F. Vaz-Imbassahy et al. 41 (RB); Santa Maria Madalena, P.E. Desengano, 15.V.2007, T. F. Vaz-Imbassahy et al. 135 (RB); Teresópolis, Cascata Feroz, V.1917, A. J. Sampaio 2702 (R 83510). SÃO PAULO: Alto da Serra, 09.IV.1921, F. C. Hoehne 676 (JE); Apiaí, 1879, J. J. Puiggari 2 (H); Cubatão, 10.IX.1986, D. M. Vital \& C. Giancotti 14004 (SP); Cunha, 22.VI.2006, D. F. Peralta et al. 3768 (SP); Eldorado, 29.IX.1984, D. M. Vital \& W. R. Buck 12439 (SP); Embu Guaçu, 14.XI.1983, O. Yano \& Y. Kida 8662 (SP); Guapiara, 16.I.1997, D. M. Vital s.n. (SP 388338); Guarujá, 4.V.2004, D. F. Peralta et al. 2396 (SP); Ibiúna, 11.III.1984, O. Yano \& T. Yano 870 (SP); Itapecirica da Serra, 19.XII.1992, O. Yano et al. 18034 (SP); Paranapiacaba, 5.V.1982, D. M. Vital 10411 (SP); Peruíbe, 3.VII.1988, O. Yano \& Z. R. Mello 11536 (SP); Ribeirão Pires, 15.II.1962, A. Baranov 148 (SP); Rio Grande da Serra, 12.VII.1961, A. Baranov 124 (SP); Salesópolis, 20.III.1991, D. M. Vital s.n. (SP 387118); Santo André, 29.VIII.1920, F. C. Hoehne 55 (SP); São Paulo, Fazenda Paranapanema, 15.VIII.1901, V. Schiffner 1333 (H); São Vicente, 18.XI.1962, B. V. Skvortzov s.n. (SP 136221); Taraguá, 21.V.1923, C. Gehrtz 618(JE); Ubatuba, 25.I.2001, D. F. Peralta 1181 (SP). PARANÁ: Morretes, 27.X.1993, O. Yano et al. 20617 (SP); Sengés, 14.VII.1982, D. M. Vital 10574 (SP); Terras CITLA, 16.I.1954, A. Sehnem 6657 a (PACA); Tijucas do Sul, 13.III.1991, R. Kummrow \& O. Guimarães 3269 (SP); Vila Velha, 7.IV.1971, D. M. Vital 1778 (SP). SANTA CATARINA: VII.1884, E. Ules.n.(JE).RIOGRANDEDOSUL:Caxias, 10.I.1947, A. Sehnem 2608 (PACA); Ciríaco, 25.IX.1984, D. M. 
Vital \& W. R. Buck 12184 (SP); Dois Irmãos, Morro Reuter, 26.II.1965, A. Sehnem 8381 (PACA); Gravataí, Itacolumi, 12.I.1950, A. Sehnem 4760 (PACA); Montenegro, 10.X.1946, A. Sehnem 2261a (PACA); Santa Cruz, Boa Vista, 12.XII.1950, A. Sehnem 5256 (PACA); São Francisco de Paula, 19.XII.1949, A. Sehnem 4605a (PACA); São Leopoldo, 22.X.1892, C. A. M. Lindman s.n. (H 2040041); Sapiranga, 11.XII.2005, D. F. Peralta et al. 3275 (SP).

É Neotropical e no Brasil está amplamente distribuída na Mata Atlântica, sendo conhecida para os estados do CE, MG, ES, RJ, SP, PR, SC e RS. Ocorre sobre tronco em decomposição, rochas, tronco, ramos e raízes de árvores, barranco e solo, freqüentemente associada a cursos de água, 0-2200 m. Status de conservação: Baixo risco (LC).

Espécie polimórfica podendo apresentar filídios lanceolados e oblongo-lanceolados a oblongos ou obovados, com ápice agudo, acuminado, obtuso, rotundo ou truncado. Esta variação pode ser encontrada no mesmo exemplar ou em coleções diferentes. Apresenta margem indistintamente bordeada por 4-5 fileiras de células mais estreitas que as da lâmina, com dentes inflados a partir do terço superior.

45. Thamniopsis pendula (Hook.) M. Fleisch., Musci Buitenzorg 3: 952. 1908. Tipo: EQUADOR. A. Humboldt \& A. Bonpland s.n. (holótipo, BM).

Fig. $21-q$

Material examinado: BRASIL. RIO DE JANEIRO: Tijuca, G. Raddi s.n. (PI).

Apresenta distribuição Neotropical (América Central e Andes setentrionais) e no Brasil é conhecida somente para o estado do RJ, ocorrendo sobre troncos de árvores, possivelmente ao nível do mar. Status de conservação: Criticamente em perigo (CR).

Este táxon foi considerado como CR no país visto que a única coleção conhecida foi realizada por Raddi há mais de 180 anos, e que tanto os esforços de coleta realizados no estado, quanto o estudo das coleções dos principais herbários do país, não resultaram em novos registros.
46. Thamniopsis purpureophylla (Müll. Hal.) W.R. Buck, Brittonia 39: 219. 1987. Tipo: BOLÍVIA. YUNGAS: H.H. Rusby 3164 (holótipo, NY, isótipo, BM). $\quad$ Fig. 2 r-v Material examinado: BRASIL. RIO DE JANEIRO: Petrópolis, Morro Assu, VIII.1915, P. Luetzelburg 6269 (JE).

Apresenta distribuição Neotropical (Colômbia, Bolívia) e no Brasil é conhecida somente para o estado do RJ, ocorrendo sobre pedras úmidas, cerca de $1200 \mathrm{~m}$. Status de conservação: Em perigo (EN).

Vaz \& Costa (2006b) excluíram esta espécie do tratamento de Pilotrichaceae para o estado, porque até aquele momento não tinham examinado nenhum material do Rio de Janeiro. Durante este estudo foi possível examinar um material coletado em 1915 para o estado. A espécie foi considerada como EN no país, visto que a única coleção conhecida foi realizada há mais de 90 anos, e que tanto os esforços de coleta realizados no estado, quanto o estudo das coleções dos principais herbários do país, não resultaram em registros recentes.

47. Thamniopsis undata (Hedw.) W.R. Buck, Brittonia 39: 219. 1987. Tipo: JAMAICA. $O$. Swartz s.n. (holótipo, G; isótipo, NY).

Material examinado: BRASIL. MINAS GERAIS: Caraça, P. Luetzelburg s.n. (JE); Lima Duarte, 12.XII.1987, Souza s.n. (SP 395329). RIO DE JANEIRO: Itatiaia, 14.X.1926, M.C.V. Bandeira s.n. (RB 174409); Nova Friburgo, 16.VII.1987, D. P. Costa et al. 319 (RB); Nova Iguaçu, Distrito de Tinguá, 29.I.2002, D. P. Costa 4093 (RB); Resende, 20.VI.1983, O. Yano 7500 (SP). SÃO PAULO: Alto da Serra, 21.IV.1920, F. C. Hoehne s.n. (JE); Cunha, 22.VI.2006, D. F. Peralta et al. 3817, 3819 (SP); Santo André, C. Gehrt 25 (SP). PARANÁ: XII.1903, P. Dusén s.n. (JE).

Apresenta distribuição Neotropical e no Brasil é conhecida para os estados do MT, MG, ES, RJ, SP, PR e SC, ocorrendo sobre troncos em decomposição, 0-2300 m. Status de conservação: Baixo risco (LC).

Pode ser confundida com espécies de Trachyxiphium, por causa do filídio lanceolado 
e da presença de alguns dentes marginais bífidos. Entretanto, é diferenciada pelos filídios fortemente ondulados, areolação conspicuamente heterogênea, células da lâmina mais largas, lisas, ápice acuminado a longo-acuminado e dentes marginais longos.

48. Trachyxiphium aduncum (Mitt.) W.R. Buck, Brittonia 39: 220. 1987. Tipo: PERU. Tarapoto, Rio Cumbasa, R. Spruce 650 (holótipo, NY).

Material examinado: BRASIL. RIO DE JANEIRO: Itatiaia, Reserva Florestal de Itatiaia, 4.IX.1924, $P$. Occhioni s.n. (RB 174398); Nova Friburgo, Macaé de Cima, J. Silva s.n. (RB 301380). SÃO PAULO: Alto da Serra, IX.1920, F.C. Hoehne 34, 83 (JE).

Conhecida para Bolívia, Peru e Brasil, onde é citada para os estados do RJ, SP e RS. Ocorre sobre pedras de rio, troncos em decomposição e raízes, 150-2200 m. Status de conservação: Dados deficientes (DD).

Características diagnósticas desta espécie incluem filídio ovado-lanceolado e ápice longoacuminado.

49. Trachyxiphium guadalupense (Brid.) W.R. Buck, Brittonia 39: 220. 1987. Tipo: GUADALUPE. s. coll. (holótipo, B!).

Material examinado: BRASIL. MINAS GERAIS: Caparaó Novo, 15.IX.1984, D. M.Vital \& W. R. Buck 11633 (SP); Itamonte, 5.VII.1991, D. M. Vital \& W. R. 19716 (SP); Monte Verde, 14.I.2006, D. F. Peralta et al. 3530 (SP). PARANÁ: Morretes, 27.X.1993, O. Yano et al. 20632 (SP). RIO DE JANEIRO: Itatiaia, trilha para Véu da Noiva, 15.II.1994, A. J. Andrade s.n. (RB 382550); Nova Friburgo, estrada de Olaria para São Lourenço, 29.III.1989, D. P. Costa et al. 859 (RB); Petrópolis, Serra da Estrela, 10.VIII.2006, T. F. Vaz-Imbassahy et al. 62, 69 (R); Rio de Janeiro, PARNA Tijuca, Corcovado, 19.VII.2006, T. F. VazImbassahy et al. 40 (R); Santa Maria Madalena, trilha para Morumbea do Imbé, 16.V.2007, T. F. VazImbassahy et al. 165 (RB); Teresópolis, Serra dos Órgãos, 31.VII.1986, A. Schäfer-Verwimp \& I. Verwimp 7393 (MO). RIO GRANDE DO SUL: Dois Irmãos, Morro Reuter, 22.II.1965, A. Sehnem 8379 (PACA); Montenegro, Linha Júlio de Castilhos, 8.XI.1949, Sehnem 4040, 4930 (PACA); São Leopoldo, Fazenda São Borja, 8.X.1941, A. Sehnem 15597 (PACA). SÃO PAULO: Alto da Serra,
3.VIII.1921, C. Gehrt 350 (SP); Apiaí, J. J. Puiggari 380 (Hookeria pilifera, JE); Campos do Jordão, 16.IX.1991, O. Yano et al. 15676 (SP); Cubatão, 10.IX.1986, D. M. Vital \& C. Giancotti 13975 (SP); Cunha, 22.VI.2006, D. F. Peralta et al. 3893 (SP); Mogi das Cruzes, 26.I.1961, G. Eiten \& L. Eiten 2499 (SP); Salesópolis, 20.III.1991, D. M. Vital s.n. (SP 387090); Santo André, 21.IV.1920, F. C. Hoehne s.n. (SP 88735).

Apresenta distribuição Neotropical e no Brasil é conhecida para as formações de Mata Atlântica das Regiões Sudeste e Sul (MG, ES, RJ, SP, PR, SC e RS). Ocorre sobre rochas, troncos e raízes de árvores, troncos em decomposição, húmus e solo, em locais muito úmidos ou associada a cursos de água, 0-1400 m. Status de conservação: Baixo risco (LC).

É caracterizado pelos filídios lanceolados a ovado-lanceolados, frequientemente falcadosecundos; ápice longo-acuminado; margem superior fortemente serreada, com dentes inflados e bífidos; células da lâmina lisas ou com papilas no ângulo apical, longo-romboidais a lineares; e costa projetada e denteada, com os dentes comumente bífidos.

50. Trachyxiphium heteroicum (Card.) W.R. Buck, Brittonia 39: 220. 1987. Tipo: MÉXICO. VERA CRUZ: Jalapa, C.G. Pringle 15145 (holótipo, G; isótipo, NY).

Material examinado: BRASIL. MATO GROSSO: Chapada dos Guimarães, 25.X.1973, G. Prance et al. 19412 (INPA). MINAS GERAIS: Conceição do Mato Dentro, 6.IX.1976, O. Yano 534 (SP). RIO DE JANEIRO: Nova Friburgo, estrada de Olaria para São Lourenço, 29.III.1989, D. P. Costa et al. 857 (RB, como Hookeriopsis rubens). RIO GRANDE DO SUL: Cambará, 25.XII.1988, A. Schäfer-Verwimp \& I. Verwimp 10630 (SP).

Conhecida somente para o México e Brasil, onde é registrada para os estados do AL, MT e RJ, sendo aqui citada pela primeira vez para MG e RS. Ocorre sobre troncos em decomposição e pedras úmidas, 230-1200 m. Status de conservação: Baixo risco (LC).

A distribuição atual no mundo e no Brasil, possivelmente não representa aquela real do táxon. Novos registros devem ampliar sua extensão de ocorrência. 
Este táxon apresenta algumas características incomuns para o gênero: filídios com costa relativamente curta, areolação quase homogênea, células da lâmina lisas, margem com quase todos os dentes simples; caulídio sem hialoderme.

51. Trachyxiphium variabile (Mitt.) W.R. Buck, Brittonia 39: 221. 1987. Tipo: BRASIL. RIO DE JANEIRO: C.A. Gardner s.n. (lectótipo, NY, designado por Buck 1987).

Fig. $2 \mathrm{w}-\mathrm{ab}$

Material examinado: BRASIL. RIO DE JANEIRO: Nova Friburgo, 27.III.1989, D. P. Costa et al. 739 (RB).

Apresenta distribuição Neotropical e no Brasil é conhecida para os estados do RJ, SP e RS, ocorrendo sobre pedras e troncos em decomposição, freqüentemente associada a cursos de água, 0-1200 m. Status de conservação: Vulnerável (VU).

A espécie apresenta distribuição restrita a quatro localidades de formações de Mata Atlântica do Sudeste e Sul do país, sendo quatro delas, Jundiaí, Nova Friburgo, Rio de Janeiro e São Francisco de Paula, não protegidas por Unidades de Conservação, e o registro mais recente realizado há cerca de 20 anos.

\section{Conclusões}

No Brasil são reconhecidas 51 espécies de Pilotrichaceae, o que representa cerca de $11 \%$ do total de espécies conhecidas para o mundo (cerca de 440 spp.) e cerca de $35 \%$ do total para o Neotrópico (cerca de 140 spp.). Este resultado demonstra a importância e a riqueza desta família de musgos no país e corrobora os dados de Gradstein et al. (2001) que destacam esta família de musgos dentre as 10 principais na América tropical. Entretanto, essa representatividade deve mudar após a realização de estudos taxonômicos nos gêneros Callicostella, Cyclodictyon e Lepidopilidium, que podem reduzir o número total de espécies tanto para a América tropical quanto para o mundo. Para o Brasil, essa redução vem ocorrendo em função dos estudos taxonômicos realizados por Vaz \& Costa (2006a,b) e Vaz-Imbassahy \&
Costa (2008a,b), que permitiram reduzir em $20 \%$ o número total de táxons citados no país. Além disso, quarenta e cinco táxons, pertencentes em sua maioria aos gêneros supracitados, foram aqui excluídos.

Em relação ao padrão de distribuição das espécies aqui analisadas, 34 (66\%) apresentam padrão Neotropical, 10 (20\%) são endêmicas do Brasil e 7 (14\%) apresentam outros tipos de distribuição. Logo, o Brasil apresenta um número elevado de espécies endêmicas, que em sua grande maioria estão restritas ao bioma Mata Atlântica, corroborando a importância deste como centro de diversidade e endemismo no país, onde se destacam as Regiões Sudeste e Sul com $86 \%$ e $60 \%$ do total de táxons. Apesar de Pilotrichaceae ser uma família com distribuição pantropical, nenhuma das espécies estudadas ocorre fora da América tropical, destacando a importância da brioflora brasileira para o Neotrópico. Cinco dos 11 gêneros ocorrentes no Brasil também são encontrados na África, corroborando os dados de Gradstein et al. (1983), que afirmam que a afinidade entre estes continentes é maior ao nível genérico.

Dos 26 estados brasileiros, 23 apresentam registros de espécies de Pilotrichaceae (Tab. 1) e somente o Maranhão, Piauí e Rio Grande do Norte não possuem citações para a família, o que reflete a carência de estudos com briófitas nestes estados, que apresentam formações vegetacionais onde a família possivelmente pode estar representada, como matas de galeria. Esses resultados também corroboram as observações de Costa \& Pôrto (2003), que consideram tanto o Maranhão quanto o Rio Grande do Norte, estados com poucas coleções de referência para briófitas depositadas nos herbários brasileiros.

Com base nos resultados encontrados, é possível afirmar que a família Pilotrichaceae ocorre principalmente nos biomas Mata Atlântica e Amazônia (Tab. 1), estando pouco representada no Planalto brasileiro, nos campos sulinos e Planalto das Guianas. As Regiões Sudeste e Sul do Brasil, que abrigam 
Tabela 1 - Espécies de Pilotrichaceae do Brasil (estados ordenados por Região). Entre parênteses é indicada a porcentagem de espécies por ${ }_{\infty}$ região. * = nova ocorrência para o estado; $* *$ = nova ocorrência para o país; negrito = endêmica do Brasil.

\begin{tabular}{|c|c|c|c|c|c|c|c|c|c|c|c|c|c|c|c|c|c|c|c|c|c|c|c|c|c|c|}
\hline Espécies/Estados & $\mathbf{R R}$ & RO & $\mathbf{A P}$ & AC & $\mathbf{A M}$ & PA & TO & MA & PI & CE & $\mathbf{R N}$ & $\mathbf{P E}$ & PB & $\mathbf{A L}$ & SE & BA & GO & MT & MS & MG & ES & RJ & SP & PR & $\mathrm{SC}$ & $\mathbf{R S}$ \\
\hline 1. Brymela fluminensis & & & & & & & & & & & & & & & & & & & & & $X$ & $\mathrm{X}$ & $\mathrm{X}$ & $X$ & & $X$ \\
\hline 2. Brymela parkeriana & & & & & $\mathrm{X}$ & $X$ & & & & & & & & & & & & $X$ & & & & & & & & \\
\hline 3. Callicostella apophysata & & & & & & & & & & & & & & & & & $X$ & & & & & $X$ & & & & \\
\hline 4. Callicostella ciliata & & & & & & & & & & & & & & & & & & $X$ & & & & & $\mathrm{X}$ & & & \\
\hline 5. Callicostella depressa & $X$ & $X$ & & $X$ & $X$ & $\mathrm{X}$ & & & & & & & & $X$ & & & & $\mathrm{X}$ & & $\mathrm{X}^{*}$ & & $X$ & $\mathrm{X}^{*}$ & & & \\
\hline 6. Callicostella martiana & & & & & & & & & & & & & & & & $\mathrm{X}$ & & $\mathrm{X}$ & & $\mathrm{X}$ & & $X$ & & $X$ & $X$ & $X$ \\
\hline 7. Callicostella merkelii & $\mathrm{X}$ & & $\mathrm{X}$ & $X$ & $X^{*}$ & $\mathrm{X}$ & & & & & & $\mathrm{X}^{*}$ & & & & & & & & $\mathrm{X}$ & & $\mathrm{X}$ & $X$ & & $\mathrm{X}$ & \\
\hline 8. Callicostella microcarpa & $\mathrm{X}$ & & & & $\mathrm{X}$ & $\mathrm{X}$ & & & & & & & & & & & & & & $\mathrm{X}$ & & $\mathrm{X}$ & $\mathrm{X}$ & & $\mathrm{X}$ & \\
\hline 9. Callicostella pallida & $\mathrm{X}$ & $X$ & $\mathrm{X}$ & $X$ & $\mathrm{X}$ & $\mathrm{X}$ & $X$ & & & $\mathrm{X}$ & & & & $\mathrm{X}$ & $X$ & $\mathrm{X}$ & $\mathrm{X}$ & $X$ & $X$ & $\mathrm{X}$ & $\mathrm{X}$ & $\mathrm{X}$ & $\mathrm{X}$ & $\mathrm{X}$ & $\mathrm{X}$ & $\mathrm{X}$ \\
\hline 10. Callicostella rufescens & & & & & $\mathrm{X}$ & $\mathrm{X}$ & & & & & & $\mathrm{X}^{*}$ & & & & & & & & & & $\mathrm{X}$ & & & & \\
\hline 11. Cyclodictyon albicans & & & & & & & & & & $\mathrm{X}$ & & $\mathrm{X}^{*}$ & & & & & & $X$ & $X$ & $X$ & & $\mathrm{X}$ & $X^{*}$ & $\mathrm{X}$ & & $\mathrm{X}$ \\
\hline 12. Cyclodictyon limbatum & & & & & & & & & & & & & & & & & & & & & & $\mathrm{X}$ & $\mathrm{X}$ & $\mathrm{X}$ & $\mathrm{X}$ & $\mathrm{X}$ \\
\hline 13. Cyclodictyon marginatum & & & & & & & & & & & & & & & & & & & & & & $\mathrm{X}^{*}$ & $X$ & $\mathrm{X}$ & & $X$ \\
\hline 14. Cyclodictyon olfersianum & & & & & & & & & & & & & & & & & & & & $X$ & & $X$ & $X$ & $X$ & $\mathrm{X}$ & $X$ \\
\hline 15. Cyclodictyon varians & & & & & $\mathrm{X}$ & & & & & & & & & & & & & & $X$ & & & $X$ & $\mathrm{X}$ & $X^{*}$ & & \\
\hline 16. Helicoblepharum brasiliensis & & & & & & & & & & & & & & & & & & & & $X$ & & & & & & \\
\hline 17. Hypnella pallescens & & $X^{*}$ & & & $X$ & $\mathrm{X}$ & & & & & & & & & & $\mathrm{X}$ & & $\mathrm{X}$ & & & & $X$ & $\mathrm{X}^{*}$ & & & \\
\hline 18. Hypnella pilifera & & & & & & & & & & & & & $X$ & & & & & & & $X$ & $X$ & $\mathrm{X}$ & $X$ & $X$ & $X$ & $\mathrm{X}$ \\
\hline 19. Hypnella punctata & & & & & & & & & & & & & & & & & & & & & & $\mathrm{X}$ & & & & \\
\hline $\begin{array}{l}\text { 20. Lepidopilidium } \\
\text { aureo-purpureum }\end{array}$ & & & & & & & & & & & & $\mathrm{X}^{*}$ & & & & & & & & & & $\mathrm{X}$ & $X$ & & $X$ & \\
\hline 21. Lepidopilidium brevisetum & & & & & & & & & & & & & & $X^{*}$ & & & & & & & $\mathrm{X}$ & $X$ & $X$ & & $\mathrm{X}$ & $X$ \\
\hline 22. Lepidopilidium laevisetum & & & & & & & & & & & & & & & & & & & & $X^{*}$ & & $\mathrm{X}$ & $X$ & $X$ & & $X$ \\
\hline 23. Lepidopilidium plebejum & & & & & & & & & & & & & & & & & & & & & & $X$ & & & $\mathrm{X}$ & $X$ \\
\hline 24. Lepidopilidium portoricense & & & & & & & & & & $X$ & & $\mathrm{X}^{*}$ & & & & & & & & & & $\mathrm{X}^{*}$ & & & $\mathrm{X}$ & \\
\hline 25. Lepidopilum affine & & & $X$ & X & $X$ & & $X$ & & & & & $X$ & & & & & $X$ & & & $X$ & & & X & $X$ & $X$ & $X$ \\
\hline
\end{tabular}




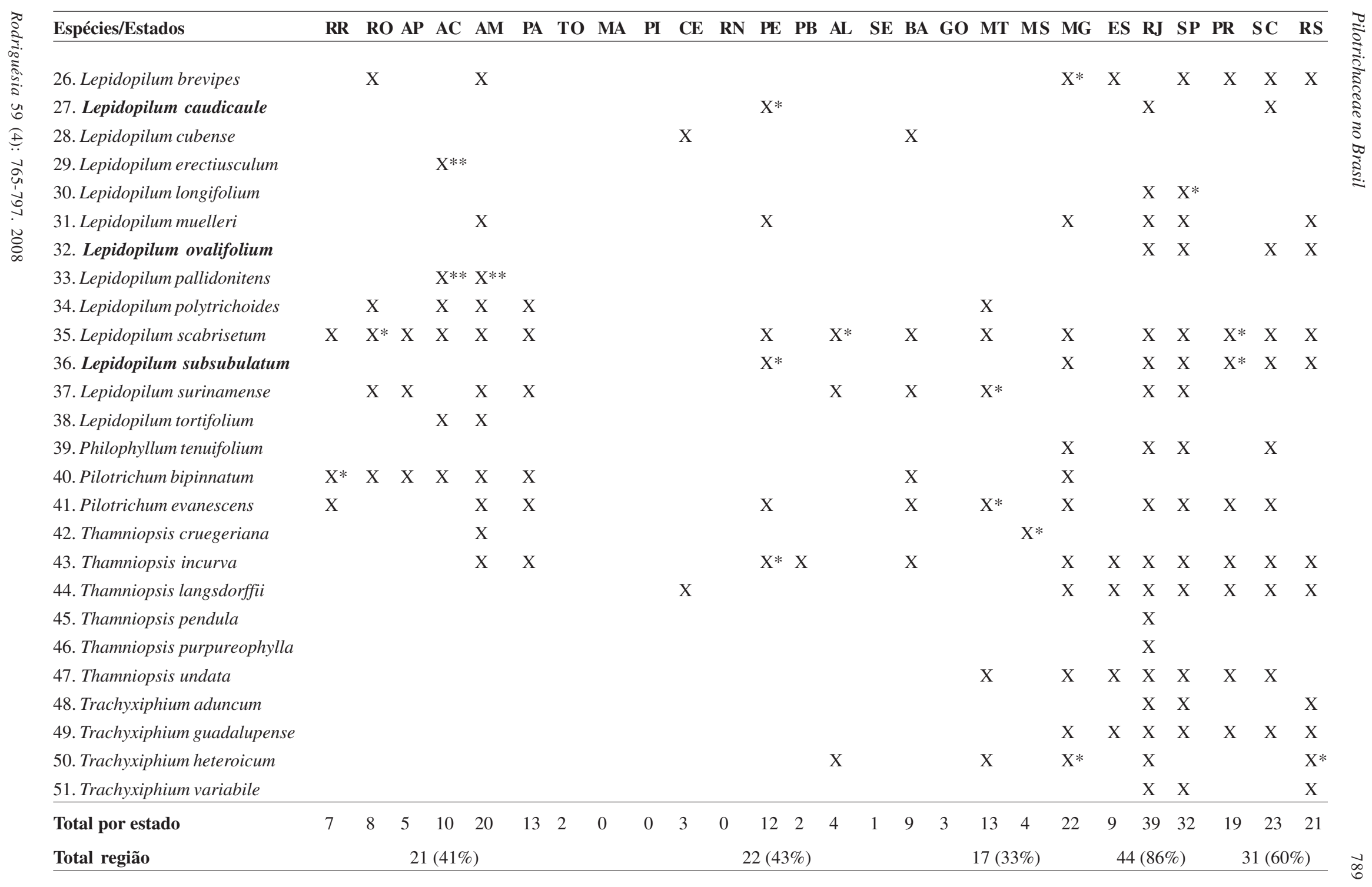


a maior parte dos remanescentes de Mata Atlântica, concentram a maior riqueza de espécies, devido às condições de umidade e luminosidade propícias para o crescimento da grande maioria dos táxons.

Das 51 espécies estudadas, duas representam novas ocorrências para o Brasil (Lepidopilum erectiusculum e L. pallidonitens) e 25 tiveram a sua distribuição ampliada para diferentes estados, destacandose Pernambuco, São Paulo e Minas Gerais. Esses resultados refletem e ressaltam a importância do estudo das coleções de briófitas depositadas em diferentes herbários no país. Além disso, indicam que muitas das espécies com atual distribuição descontínua podem ter sua distribuição ampliada através de esforços de coleta em áreas reconhecidas como lacunas do conhecimento.

Neste trabalho também foi avaliado o status de conservação das espécies de Pilotrichaceae para o país, e os resultados demonstram que a grande maioria dos táxons não estão ameaçados, e, do total de 51, 35 (68\%) foram caracterizados como de Baixo Risco (LC); quatro (8\%) como Vulneráveis
(Brymela fluminensis, Cyclodictyon olfersianum, Lepidopilum longifolium e Trachyxiphium variabile); um (2\%) como Em Perigo (EN - Thamniopsis purpureophylla); e dois (4\%) como Criticamente em Perigo (CR - Hypnella punctata e Thamniopsis pendula). Entretanto, nove espécies (18\%) estão incluídas em Dados Deficientes (DD), o que demonstra a necessidade de estudos em formações vegetacionais ou áreas reconhecidas como lacunas do conhecimento para a brioflora no país. O fato da maior parte das espécies apresentar baixo risco está possivelmente relacionado à ampla distribuição da família no país e de grande parte dos remanescentes do bioma Mata Atlântica encontrarem-se protegidos em Unidades de Conservação.

Os resultados encontrados neste estudo para a família Pilotrichaceae no Brasil, ainda evidenciam a necessidade da realização de estudos taxonômicos para determinados gêneros, de esforços de coleta em áreas reconhecidas como lacunas no conhecimento e de estudo das coleções desta família depositadas em diferentes herbários.

\section{Espécies excluídas por serem consideradas registros errôneos}

Callicostella papillata (Mont.) Mitt.

Cyclodictyon cuspidatum O. Kuntze

Hemiragis aurea (Brid.) Renauld \& Cardot

Hypnella cymbifolia (Hampe) A. Jaeger

Hypnella leptorrhyncha (Hook. \& Greville)

A. Jaeger

Hypnella obtusissima Müll. Hal.
Lepidopilum amplirete (Sull.) Mitt.

Lepidopilum beyrichii Hampe

Lepidopilum curvirameum (Müll. Hal.) Paris

Lepidopilum regnelli (Ångstr.) Broth.

Lepidopilum subfulvum Mitt.

Lepidopilum subulatum Mitt.

Schizomitrium cirrhosum (Hampe) W.R. Buck

\section{Espécies excluídas por serem registros duvidosos}

Aqui estão incluídas 45 espécies consideradas pouco conhecidas do ponto de vista taxonômico pertencentes a gêneros que necessitam de revisão como Callicostella, Cyclodictyon e Lepidopilidium, e cuja grande maioria é conhecida somente pela coleção tipo.

Callicostella glabrata Broth. - AM, nível do mar. Brasil.

Callicostella irrorata (Müll. Hal.) Broth. SP, sem altitude. Brasil.
Callicostella jungermannioides Herzog - PI e BA, sem altitude. Brasil.

Callicostella juruensis Broth. - AM, 0-200 m. Brasil. 
Callicostella limosa (Broth.) Broth. - SP, nível do mar. Brasil.

Callicostella monofaria (Geh. \& Hampe) Broth. - SP, ca. 80 m. Brasil.

Callicostella mosenii (Broth.) Broth. - SP, nível do mar. Brasil.

Callicostella paulensis Broth. - BA, MG, SP e RJ, 0-600 m. Brasil.

Callicostella pellucida (Mitt.) A. Jaeger AM, 0-200 m. Brasil.

Callicostella perpallida (Broth.) Broth. - SP e PR, 0-600 m. Brasil.

Callicostella pilotrichidioides Broth. - GO, sem altitude. Brasil.

Callicostella sellowiana (Hampe) A. Jaeger - Sem localidade e altitude. Brasil.

Callicostella spurio-pallida (Broth.) Broth. - SP, 0-900 m. Brasil.

Callicostella submicrocarapa (Geh. \& Hampe) Broth. - SP, nível do mar. Brasil.

Callicostella submonofaria Broth. - SP, nível do mar. Brasil.

Cyclodictyon aciculifolium (Müll. Hal.) Broth. - SC, ca. 800 m. Brasil.

Cyclodictyon albatum (Müll. Hal.) O. Kuntze

- SC, sem altitude. Brasil.

Cyclodictyon chloroleucu (Broth.) Broth. SP, sem altitude. Brasil.

Cyclodictyon glaucifolium (Müll. Hal.)

Broth. - MG, ca. 1500 m. Brasil.

Cyclodictyon glareosum (Broth.) Broth. MG, SP, PR e RS, 60-940 m. Brasil.

Cyclodictyon iporangeanum (Geh. \& Hampe) Broth. - SP e SC, nível do mar. Brasil. Cyclodictyon laxifolium Herzog - RJ, ca. 1000 m. Brasil.

Cyclodictyon leucomitrium (Müll. Hal.) Broth. - RJ, PR, SC e RS, 0-1000 m. Brasil.

Cyclodictyon longifrons (Broth.) Broth. - SP, ca. $680 \mathrm{~m}$. Brasil.

Cyclodictyon minarum (Ångstr.) O. Kuntze - MG e RS. ca. 300 m. Brasil.
Cyclodictyon minus (úngstr.) O. Kuntze - SC e RS, 0-150 m. Brasil.

Cyclodictyon molliculum (Broth.) Broth. MG, PR, SC e RS, 800-1600 m. Brasil.

Cyclodictyon pergracile Broth. - SP, ca. 750 m. Brasil.

Cyclodictyon regnellianum (Müll. Hal.) M. Fleisch. - MG e SP, 680- 1100 m. Brasil.

Cyclodictyon regnellii (Ångstr.) O. Kuntze MG, SP, PR e RS, 0-300 m. Neotropical.

Cyclodictyon rivale (Müll. Hal.) Broth. - MG, RJ e RS, 180-600 m. Brasil.

Cyclodictyon submarginatum (úngstr.) O. Kuntze - MG e RS, 900-1100 m. Brasil.

Cyclodictyon vatteri Bartram - MT, ca. 100 m. Brasil.

Cyclodictyon viridissimum O. Kuntze - MG, ca. 1100 m. Brasil.

Hookeriopsis corcovadensis (Reichdt.) A. Jaeger - RJ, ca. 700 m. Brasil.

Hookeriopsis vesicularia (Müll. Hal.) Broth. - MG e PR, 900-2000 m. Brasil.

Lepidopilidium entodontella (Broth.) Broth. - SP e RJ, ca. 800. Brasil.

Lepidopilidium gracilifrons (Müll. Hal.) Broth. - BA, MG, SP e RS, nível do mar. Brasil.

Lepidopilidium nitens (Hornsch.) Broth. MG, SP, RJ e SC, 0-960 m. Brasil.

Lepidopilidium proligerum Broth. \& Sébile - SP, ca. 560 m. Brasil.

Lepidopilidium regnellii (Ångstr.) Broth. RS, sem altitude. Brasil.

Lepidopilidium rupestre (Müll. Hal.) Broth. - SC, ca. 960 m. Brasil.

Lepidopilidium wainioi (Broth.) Broth. - MG e RJ, ca. 1300 m. Brasil.

Lepidopilum glaziovii Hampe - RJ e SP, 0960 m. Brasil.

Lepidopilum mosenii Broth. - SP e PR, sem altitude. Brasil. 
Lista de sinônimos

Callicostella aspera (Mitt.) A. Jaeger = Callicostella pallida (Hornsch.) Ångstr. (fide Florschütz-de Waard 1986).

Callicostella daltoniaecarpa (Müll. Hal.) Broth. = Lepidopilum subsubulatum Geh. \& Hampe (syn. fide Vaz \& Costa 2006b).

Callicostella paludicola Broth. = Callicostella merkelii (Hornsch.) A. Jaeger (syn. fide Churchill \& Fuentes 2005).

Cyclodictyon laxifolium Herzog = Cyclodictyon albicans (Hedw.) O. Kuntze (syn. fide Vaz \& Costa 2006a).

Cyclodictyon glaucifolium (Müll. Hal.) Broth. = Cyclodictyon albicans (Hedw.) O. Kuntze (syn. fide Vaz \& Costa 2006a).

Hookeriopsis armata Bartr. = Trachyxiphium guadalupense (Brid.) W. R. Buck (syn. fide Vaz-Imbassahy \& Costa 2008b).

Hookeriopsis bartramii Sehnem = Thamniopsis langsdorffii (Hook.) W. R. Buck (syn. fide Vaz-Imbassahy \& Costa 2008b).

Hookeriopsis brachypelma Müll. Hal. = Thamniopsis langsdorffii (Hook.) W. R. Buck (syn. fide Vaz-Imbassahy \& Costa 2008b).

Hookeriopsis heterophylla Sehnem = Thamniopsis langsdorffii (Hook.) W. R. Buck (syn. fide Vaz-Imbassahy \& Costa 2008b).

Hookeriopsis hydrophila (Müll. Hal.) Broth. = Thamniopsis langsdorffii (Hook.) W. R. Buck (syn. fide Vaz-Imbassahy \& Costa 2008b).

Hookeriopsis latifrondea (Müll. Hal.) Broth. = Thamniopsis undata (Hedw.) W. R. Buck (syn. fide Vaz-Imbassahy \& Costa 2008b).

Hookeriopsis lonchopelma (Müll. Hal.) Broth. = Thamniopsis langsdorffii (Hook.) W. R. Buck (syn. fide Vaz-Imbassahy \& Costa 2008b).

Hookeriopsis minutiretis (Müll. Hal.) Broth. = Thamniopsis langsdorffii (Hook.) W. R.
Buck (syn. fide Vaz-Imbassahy \& Costa 2008b).

Hookeriopsis perfulva (Müll. Hal.) M. Fleischer = Trachyxiphium guadalupense (Brid.) W. R. (syn. fide Vaz-Imbassahy \& Costa 2008b).

Hookeriopsis puiggarii (Geh. \& Hampe) Broth. = Thamniopsis langsdorffii (Hook.) W. R. Buck (syn. fide Vaz-Imbassahy \& Costa 2008b).

Hookeriopsis rhynchostegioides (Broth.) Broth. = Thamniopsis langsdorffii (Hook.) W. R. Buck (syn. fide Vaz-Imbassahy \& Costa 2008b).

Hookeriopsis rubens (Müll. Hal.) Broth = Thamniopsis langsdorffii (Hook.) W. R. Buck (syn. fide Vaz-Imbassahy \& Costa 2008b).

Hookeriopsis serrata (Aongstr.) A. Jaeger = Thamniopsis langsdorffii (Hook.) W. R. Buck (syn. fide Vaz-Imbassahy \& Costa 2008b).

Hypnella pseudo-pilifera (Hampe) A. Jaeger = Hypnella leptorrhyncha (Hook. \& Grev.) A. Jaeger (syn. fide Crosby et al. 1985).

Lepidopilum flavescens Geh. \& Hampe $=$ Lepidopilum subsubulatum Geh. \& Hampe (syn. fide Vaz \& Costa 2006b).

Lepidopilum laxirete Müll. Hal. = Lepidopilum brevipes Mitt. (syn. fide Churchill 1988).

Lepidopilum pacimonense Spruce = Lepidopilum affine Müll. Hal. (syn. fide Churchill 1988).

Lepidopilum pycnodictyon Müll. Hal. = Lepidopilum subsubulatum Geh. \& Hampe (syn. fide Chuchill 1988).

Lepidopilum oblongifolium Mitt. = Lepidopilum scabrisetum (Schwägr.) Steere (syn. fide Churchill 1988).

Lepidopilum subaurifolium Geh. \& Hampe = Lepidopilum subsubulatum Geh. \& Hampe (syn. fide Chuchill 1988).

Thamniopsis beyrichiana (Hampe) Broth. = 
Thamniopsis langsdorffii (Hook.) W. R. Buck (syn. fide Vaz \& Costa 2006b).

Thamniopsis stenodictyon (Sehnem) Oliveira-e-Silva \& Yano = Thamniopsis langsdorffii (Hook.) W. R. Buck (syn. fide

\section{Agradecimentos}

Os autores agradecem aos curadores dos herbários consultados pela disponibilidade e acesso às coleções e/ou empréstimo de material, ao Dr. Steven Churchill e ao Dr. Bruce Allen, ambos do Missouri Botanical Garden, ao primeiro pela contribuição durante a análise do status taxonômico das espécies e ao segundo por disponibilizar a ilustração de Hypnella punctata, e ao Instituto de Pesquisas Jardim Botânico do Rio de Janeiro, por toda infra-estrutura e recursos disponibilizados. A primeira autora agradece ao CNPq pela bolsa de doutorado concedida, sem a qual a maior parte deste trabalho não teria sido realizado.

\section{REFERÊNCIAS BIBLIOGRÁFICAS}

Allen, B. 1986. The taxonomic status of Hypnella punctata. The Bryologist 89: 224-226.

Ångström, J. 1876. Primae linae muscorum cognoscendorum, qui ad Caldas Brasilia sunt collecti. I. Musci frondose et Sphagna. II. Hepaticae. Öfversigt af Kugl Vetenskaps-Akademiens Förhandlingar 33: 3-55; 33: 77-92.

Bastos, C. J. P. \& Vilas Bôas-Bastos, S. B. 1998. Adições à brioflora (Bryopsida) do Estado da Bahia, Brasil. Tropical Bryology 15: 111-116.

Brotherus, V. F. 1900. Die Laubmoose der ersten Regnellschen Expedition. Bihang til Kongliga Svenska VetenskapsAkademiens Handlingar 26, 3: 65 pp. . 1907. Bryales, in part. Die Natürlichen Pflanzenfamilien 1: 961-1008. . 1925. Musci (Laubmoose). 2. Hälfte. In: A. Engler \& K. Plantl (eds). Die Natürlichen Pflanzenfamilien. Leipzip.
Vaz-Imbassahy \& Costa 2008a).

Trachyxiphium hypnaceum (Müll. Hal.) W.R. Buck = Trachyxiphium guadalupense (Brid.) W. R. (syn. fide Vaz \& Costa 2006a).

Buck, W. R. 1987. Taxonomic and nomenclatural rearrangement in the Hookeriales with notes on West Indian taxa. Brittonia 39: 210-224. 1998. Pleurocarpous Mosses of The West Indies. Memoirs of The New York Botanical Garden 82: 1-400. 1992. A Revision of Philophyllum (Hookeriales). The Bryologist 95: 334-337. ; Cox, C. J.; Shaw, A. J. \& Goffinet, B. 2005. Ordinal relationships of pleurocarpous mosses, with special emphasis on the Hookeriales. Systematics and Biodiversity 2: 121-145.

\& Goffinet, B. 2000. Morphology and classification of mosses. Pp. 71-123. In: A.J. Shaw \& B. Goffinet (eds.). Bryophyte Biology. Cambridge University Press, England.

Câmara, P. E. A. S.; Oliveira, J. R. P. M. \& Macedo Santiago, M. M. 2005. A checklist of the bryophytes of Distrito Federal (Brasília, Brazil). Tropical Bryology 26: 133-140.

Churchill, S. P. 1988. Revision of moss Genus Lepidopilum (Callicostaceae). PhD. Dissertation. City University of New York.

1998. Catalog of Amazonian mosses. The Journal of the Hattori Botanical Laboratory 85: 191-238.

Churchill, S. P. \& Fuentes, C. A. 2005: Additions, combinations, and synonyms for the Bolivian moss flora. Tropical Bryology 26: 119-132.

Costa, D. P.; Imbassahy, C. A. A. \& Silva, V. P. A. V. 2005a. Diversidade e importância das espécies de briófitas na conservação dos ecossistemas do estado do Rio de Janeiro. Rodriguésia 56: 13-49. 
;___ \&_. 2005b. Checklist and distribution of the mosses, liverworts and hornworts of Rio de Janeiro State, Brazil. The Journal of the Hattori Botanical Laboratory 98: 259-298.

\& Porto, K. C. 2003. Estado da arte das coleções de briófitas no Brasil. Pp. 75-98. In: A. L. Peixoto (org.). Coleções biológicas de apoio ao inventário, uso sustentável e conservação da biodiversidade. Instituto de Pesquisas Jardim Botânico do Rio de Janeiro, Rio de Janeiro.

\& Yano. O. 1995. Musgos do Município de Nova Friburgo, Rio de Janeiro, Brasil. Arquivos do Jardim Botânico do Rio de Janeiro 33: 99-118.

Crosby, M. R. 1969. A revision of the tropical American moss genus Pilotrichum. The Bryologist 72: 275-343.

. 1974. Towards a revised classification of the Hookeriaceae (Musci). The Journal of the Hattori Botanical Laboratory 38: 129-141.

; Magill, R. E. \& Allen, B. 1985. A review of the moss genus Hypnella. The Bryologist 88: 121-129.

; Magill, R. E.; Allen, B. \& He, S. 1999. A checklist of the mosses. Missouri Botanical Garden, St. Louis.

Crum, H. 1984. Notes on tropical American mosses. The Bryologist 87: 203-216.

Florschütz-de Waard, J. 1986. Musci. Part II. Pp. 273-361. In: A. L. Stoffers \& J. C. Lindeman (eds.), Flora of Suriname. v. 6. Brill, Leiden.

Ganacevich, N. A. \& Mello, Z. R. 2006. Briófitas da Biquinha de Anchieta, São Vicente, São Paulo, Brasil. Boletim do Instituto de Botânica 18: 75-84.

Genevro, J. A.; Athayde Filho, F. P. \& Peralta, D. F. 2006. Briófitas de mata de galeria no Parque Municipal Mário Vianna, Nova Xavantina, Mato Grosso, Brasil. Boletim do Instituto de Botânica 18: 149-157.

Goffinet, B. \& Buck, W. R. 2004. Systematics of the Bryophyta(Mosses): from molecules to a revised classification. In: Goffinet, B.
Hollowell, V.\& Magill, R. (eds.). Molecular systematics of bryophytes. Missouri Botanical Garden Press, St Louis. Pp. 205-239.

Gradstein, S. R. ; Pócs, T. \& Vána, J. 1983. Disjunct hepaticae in tropical America and Africa. Acta Botanica Hungarica 29: 127-171.

; Churchill, S. P. \& Salazar-Allen, N. 2001. Guide to the bryophytes of tropical America. Memoirs of The New York Botanical Garden 86: 1-577.

Hallinbäck, T. \& Hodgetts, N. 2000. Mosses, liverworts \& hornworts: a status survey and conservation action plan for bryophytes. IUCN, Gland, 106p.

Hampe, E. 1872. Musci frondosi. Pp. 36-59. In: Warming (ed.). Symbolae ad floram Brasiliae centrales cognoscendam. Videnskabelige Meddelelser fra dansk naturhistoriske Forening i Kjöbenhavn, ser. 3, 10 .

1874a. Musci frondosi. Pp. 129-178. In: Warming (ed.). Symbolae ad floram Brasiliae centrales cognoscendam. Videnskabelige Meddelelser fra dansk naturhistoriske Forening i Kjöbenhavn, ser. 3, 19.

1874b. Musci frondosi. Pp. 73-141. In: Warming (ed.). Symbolae ad floram Brasiliae centrales cognoscendam. Videnskabelige Meddelelser fra dansk naturhistoriske Forening i Kjöbenhavn, ser. 3, 19.

1877. Musci frondosi. Pp. 251-274. In: Warming (ed.). Symbolae ad floram Brasiliae centrales cognoscendam. Videnskabelige Meddelelser fra dansk naturhistoriske Forening i Kjöbenhavn, ser. 3, 24.

1879. Enumeratio muscorum hactenus in provinciis Brasiliensibus Rio de Janeiro et São Paulo detectorum. Videnskabelige Meddelelser fra dansk naturhistoriske Forening i Kjöbenhavn 26: 73-164.

Joyce, M. V.; Mello, Z. R. \& Yano, O. 2006. Briófitas da Ilha de Palmas, Guarujá, São Paulo, Brasil. Boletim do Instituto de Botânica 18: 101-109. 
Kindberg, N. C. 1899. Studien über dei Systematik der pleurokarpischen Laubmoose. II. Botanisches Centralblatt 77: 19-55.

Lisboa, R. C. L. 1994. Adições à flora do estado do Pará. Boletim do Museu Paraense Emílio Goeldi, Série Botânica, 10: $15-42$.

\& Ilkiu-Borges, A.L. 1996. Briófitas da Serra dos Carajás e sua possível utilização como indicadores da poluição urbana. Boletim do Museu Paraense Emílio Goeldi, Série Botânica, 12: 161-181. \& 1997. Novas ocorrências de Bryophyta (musgos) para o estado do Pará. Acta Amazonica 27: 81-102.

; Lima, M. J. L. \& Maciel, U. N. 1999. Musgos da Ilha de Marajó - II - Município de Anajás, Pará, Brasil. Acta Amazonica 29: 201-206.

\& Maciel, U. N. 1994. Musgos da ilha de Marajó - I - Afuá (Pará). Boletim do Museu Paraense Emílio Goeldi, Série Botânica, 10: 43-55.

; Muniz, A. C. M. \& Maciel, U. N. 1998. Musgos da Ilha de Marajó - III - Chaves (Pará). Boletim do Museu Paraense Emílio Goeldi, Série Botânica, 14: 117-125.

; Tavares, A. C. C. \& Costa Neto, S. V. 2006. Musgos (Bryophyta) e hepáticas (Marchantiophyta) da zona costeira do estado do Amapá, Brasil. Boletim do Instituto de Botânica 18: 163-171.

Luizi-Ponzo, A. P., Bastos, C. J. P., Costa, D. P., Pôrto, K. C., Câmara, P. E. A. S., Lisboa, R. C. L. \& Vilas Bôas-Bastos, S. B. 2006. Glossarium Polyglottum Bryologiae - Versão brasileira do glossário briológico. Universidade Federal de Juiz de Fora, Juiz de Fora, 114p.

Miller, H. A. 1971. An overview of the Hookeriales. Phytologia 21: 243-252.

Mitten, W. 1869. Musci Austro-Americani. Journal of the Linnean Society, Botany 12: 1-659.

Müller, C. 1898. Bryologia Serrae Itatiaiae. Bulletin de L'Herbier Boissier 6: 18-48.
1900. Symbolae ad bryologiam Brasiliae et regionorum vicinarum. Hedwigia 39: 235-289.

Oliveira, H. C. \& Alves, M. H. 2007. Adições à flora do estado do Ceará, Brasil. Rodriguésia 58: 1-11.

Oliveira-e-Silva, M. I. M. N. \& Yano, O. 1998. Thamniopsis stenodictyon (Sehnem) Oliveira-e-Silva \& Yano, comb. nov. Bradea 8: 81-84. \& 2000. Musgos de Mangaratiba e Angra dos Reis, Rio de Janeiro, Brasil. Boletim do Instituto de Botânica 14: 1-137.

Paixão, R. C. \& Mello, Z. R. 2006. Brioflora ao longo da trilha do costão, Peruíbe, São Paulo, Brasil. Boletim do Instituto de Botânica 18: 85-90.

Peralta, D. F. \& Yano, O. 2005. Briófitas de mata paludosa, município de Zacarias, noroeste do estado de São Paulo, Brasil. Acta Botanica Brasilica 19: 963-977. \& 2006. Novas ocorrências de musgos (Bryophyta) para o estado de São Paulo, Brasil. Revista Brasileira de Botânica 29: 49-65.

Pôrto, K. C. 1990. Bryoflores d'une forêt de plaine et d'altitude moyenne dans l'état de Pernambuco (Brés.): Analyse floristique. Cryptogamie, Bryologie et Lichénologie 11: 109-161.

Santos, R. C. P. \& Lisboa. R. C. L. 2003. Musgos (Bryophyta) do Nordeste Paraense, Brasil - 1 - Zona Bragantina, Microrregião do Salgado e Município de Viseu. Acta Amazonica 33: 415-422.

Schäfer-Verwimp, A. 1989. New or interesting records of Brazilian bryophytes, II. The Journal of the Hattori Botanical Laboratory 67: 313-321.

1992. New or interesting records of Brazilian bryophytes, III. The Journal of the Hattori Botanical Laboratory 71: 55-68.

Sehnem, A. 1979. Musgos sul-brasileiros. v. 6. Pesquisas, Série Botânica 33: 1-149.

Souza A. P. S. \& Lisboa, R. C. L. 2005. Musgos (bryophyta) na Ilha Trambioca, 
Barcarena, PA, Brasil. Acta Botanica Brasilica 19: 487-492.

Valdevino, J. A.; Sá, P. S. \& Pôrto, K. C. 2002. Musgos pleurocárpicos de mata serrana em Pernambuco, Brasil. Acta Botanica Brasilica 16: 161-174.

Vaz, T. F. \& Costa, D. P. 2006a. Os gêneros Brymela, Callicostella, Crossomitrium, Cyclodictyon, Hookeriopsis e Hypnella (Pilotrichaceae, Bryophyta) no estado do Rio de Janeiro, Brasil. Acta Botanica Brasilica 20: 955-973.

\&__. 2006b. Os gêneros Lepidopilidium, Lepidopilum, Pilotrichum e Thamniopsis (Pilotrichaceae, Bryophyta) no estado do Rio de Janeiro, Brasil. Acta Botanica Brasilica 20: 975-993.

Vaz-Imbassahy, T. F. \& Costa, D.P. 2008a. The Pilotrichaceae (Hookeriales) of Rio de Janeiro, Brazil. The Bryologist 111(4): 551-575.

$\& \_$. 2008b. New combinations and new synonyms in Pilotrichaceae (Bryophyta). Nova Hedwigia 87(1-2): 237-246.

Vilas Bôas-Bastos, S. B. \& Bastos, C. J. P. 2002. Occurence of the genus Pilotrichum P. Beauv. (Pilotrichaceae, Bryopsida) in the state of Bahia, Brazil. Nova Hedwigia 75: 127-225.

$\&$ 2004. Note on the occurence of Hypnella pallescens (Hook.) A. Jaeger (Bryophyta, Pilotrichaceae) in Bahia, Brazil. Acta Botanica Malacitana 29: 260-263.

Visnadi, S. R. 2004. Briófitas de praias do Estado de São Paulo, Brasil. Acta Botanica Brasilica 18: 91-97.

\& Vital, D. M. 2000. Lista de Briófitas ocorrentes no Parque Estadual das Fontes do Ipiranga - PEFI. Hoehnea 27: 279-294.

Vital, D. M. \& Visnadi, S. R. 2000. New records and notes on Brazilian bryophytes. The Journal of the Hattori Botanical Laboratory 88: 191-197.

Vitt, D. H. 1984. Classification of the Bryopsida. In: Schuster, R. M. (ed.). New Manual of Bryology. v. 2. The Hattori Botanical Laboratory, Nichinan. Pp. 676-759.

Whittemore, A. \& Allen, B. 1989. The systematic position of Adelothecium Mitt. and the familial classification of the Hookeriales (Musci). The Bryologist 92: 261-272.

Wijk, R. van der, Margadant, W. D. \& Florschütz, P. A. 1959-1969. Index Muscorum. I-V. Regnum Veg. 17, 26, 33, 48, 65. International Association for Taxonomy. Utrecht.

Yano, O. 1981. Checklist of Brazilian mosses. The Journal of the Hattori Botanical Laboratory 50: 279-456. 1985. Redescoberta de Itatiella, Peltolejeunea e Philophyllum no Estado de São Paulo, Brasil. Rickia 12: 155-163. 1989. An additional checklist of Brazilian bryophytes. The Journal of the Hattori Botanical Laboratory 66: 373-434. 1995. A new additional annoted checklist of Brazilian bryophytes. The Journal of the Hattori Botanical Laboratory 78: 137-182.

1996. A checklist of the Brazilian bryophytes. Boletim do Instituto de Botânica 10: 47-232.

2006. Novas adições ao catálogo de briófitas brasileiras. Boletim do Instituto de Botânica 17: 1-142.

\& Bastos, C. J. P. 2004. Adições à flora de briófitas de Mato Grosso do Sul, Brasil. Acta Botanica Brasilica 18: 437-458.

\& Câmara, P. E. A. S. 2004. Briófitas de Manaus, Amazonas, Brasil. Acta Amazonica 34: 445-457.

\& Colletes, A. G. 2000. Briófitas do Parque Nacional de Sete Quedas, Guairá, PR, Brasil. Acta Botanica Brasilica 14: 215-242.

\& Costa, D. P. 2000. Flora dos estados de Goiás e Tocantins. Criptógamas: Briófitas. v. 5. Ed. UFG.

\& Lisboa, R. C. L. 1988. Briófitas do território federal do Amapá, Brasil. Boletim do Museu Paraense Emílio Goeldi, Série Botânica, 4: 243-270. 
\& Mello, Z. R. 1992. Briófitas novas para o estado de Roraima, Brasil. Acta Amazonica 22: 23-50.

; \& Colletes, A. G. 2003. Briófitas da Ilha Urubuqueçaba, São Paulo, Brasil. Iheringia, Série Botânica, 58: 195-214.

\& Peralta, D. F. 2004. Musgos (Bryophyta) de Mato Grosso, Brasil. Hoehnea 31: 251-292. $\&$ . 2006a. Novas ocorrências de briófitas para os estados de Alagoas e
Sergipe, Brasil. Arquivos do Museu Nacional 64: 287-297.

$\&$

2006b. Briófitas coletadas por Daniel Moreira Vital no estado da Bahia, Brasil. Boletim do Instituto de Botânica 18: 33-73. $\&$ 2007. Briófitas da Ilha do Bom Abrigo, estado de São Paulo, Brasil. Hoehnea 34: 87-94.

\& Pôrto, K. C. 2006. Diversidade das briófitas das matas serranas do Ceará, Brasil. Hoehnea 33: 7-39. 
